This item was submitted to Loughborough's Research Repository by the author.

Items in Figshare are protected by copyright, with all rights reserved, unless otherwise indicated.

\title{
A hybrid model for a drilling process for hydrocarbon well-boring operations
}

\section{PLEASE CITE THE PUBLISHED VERSION}

https://doi.org/10.1177/1464419317697854

\section{PUBLISHER}

SAGE Publishing ( $\mathrm{IMechE}$

\section{VERSION}

AM (Accepted Manuscript)

\section{PUBLISHER STATEMENT}

This work is made available according to the conditions of the Creative Commons Attribution-NonCommercialNoDerivatives 4.0 International (CC BY-NC-ND 4.0) licence. Full details of this licence are available at: https://creativecommons.org/licenses/by-nc-nd/4.0/

\section{LICENCE}

CC BY-NC-ND 4.0

\section{REPOSITORY RECORD}

Alkaragoolee, M.Y.A., Kambiz Morteza Ebrahimi, and R. Whalley. 2018. "A Hybrid Model for a Drilling Process for Hydrocarbon Well-boring Operations”. figshare. https://hdl.handle.net/2134/33360. 


\title{
A Hybrid model for a Drilling Process for Hydrocarbon Well Boring Operations
}

\author{
M Y A Alkaragoolee ${ }^{1}, \mathrm{~K} \mathrm{M} \mathrm{Ebrahimi}^{2}$ and $\mathrm{R}$ Whalley ${ }^{3}$ \\ ${ }^{1}$ School of Engineering, University of Bradford \\ ${ }^{2}$ Aeronautical and Automotive Engineering, Loughborough University, \\ ${ }^{3}$ British University in Dubai
}

\begin{abstract}
In hydrocarbon well drilling operations, self-excited, stick-slip vibration is considered as a source of drilling equipment failures which also cases a reduction in drilling penetration. This leads to delays and increasing operational and equipment costs. A new approach using distributed -lumped (hybrid) modelling is considered as the first step in understanding stick-slip phenomena in order to determine a solution to this problem. In this paper a hybrid modelling scheme is the advocated modelling method proposed in contrast to conventional lumped modelling. Three case studies are used to show that hybrid modelling is an accurate technique in the representation of stick-slip oscillations, particularly when the length of the Drill string is high. The results show the modelling technique adopted in this work can present the phenomena associated with stick-slip process more accurately.
\end{abstract}

Keywords: Drilling, Stick-Slip, Distributed-Lumped, hydrocarbon well.

\section{1-Introduction}

The production of oil and gas necessitates drilling small bore holes in the earth's surface, using a rotary system. The equipment used comprises a hoisting system, motor, fluid circulating and a monitoring system (1). This system, as shown in Figure 1, creates a bore well by cutting rock, either by chipping or by using a crushing action.

The energy required for rock cutting provided by the motor torque is transmitted to the cutting drill bit by a long shaft known as the drill string. The drill string consists of a drill pipe, heavyweight drill pipe (HWDP) and bottom hole assembly (BHA). The drill pipe is a heat-treated alloy steel, tube. The length of the drill pipe ranges from 5.5 to $13.7 \mathrm{~m}$ with a typical length of $9 \mathrm{~m}$. The 
outer diameter of the drill pipe ranges from 7.3 to $14 \mathrm{~cm}$. The heavy-weight drill pipe (HWDP) is used as an intermediate connection to the drill collar, with the same outer diameter as the drill pipe(2). This transition section between the drill pipe and drill collar is used to reduce the stress between the two and to prevent failure in the area of this connection. The drill collars form the lowset part of the drill string with a length of $9 \mathrm{~m}$ and the outer diameter of $320 \mathrm{~mm}$ and with an inner diameter less than the inner diameter of the drill pipe. This has several functions, such as loading the drill bit (WOB), keeping the drill pipe in tension and introducing the pendulum effect in order to improve the accuracy of the operation.

The cutting debris from drilling is removed from the bore hole via a fluid circulation system. Mud is pumped into the top of the drill string and exits through an orifice in the drill bit. This fluid is returned using the annulus between the drill string and the bore hole wall.

Drilling operations generate three modes of vibration. These are torsional (stick-slip oscillation), longitudinal (drill bit bouncing displacement) and lateral vibration which result in whirl motion(2). At lower speeds, stick-slip vibration is considered the most damaging compared to the other types of oscillation $(3,4)$. The stick-slip vibration means that the top of the drill string rotates at a constant speed while the speed of the drill bit fluctuation between zero and up to three times that of the top speed, as indicated in Figure 2, which is from(5).

The phenomena of stick-slip arise from a trapped drill collar while the rotary table continues to turn. When the applied torque due to the" wound up" drill pipe overcomes the tapped torque, the drill bit begins rotating at high speed. This high speed leads to a torsional wave which travels towards the rotary table to then be reflected the rear assembly. This process may be repeated many times until the stick-slip action disappears. Stick-slip may occur during $50 \%$ of the time of drilling $(5,6)$ leading to severe axial and lateral vibrations at the bottom-hole assembly $(\mathrm{BHA})$.

Due to vibration, many problems occur during drilling operations such as fatigue in the drill pipe(5), failure of the drill string components $(5,7)$, instability of the wellbore $(8)$ and drill bit damage $(6,9,10)$.

This paper focuses on two types of stick-slip modelling. First, a lumped model with two degrees of freedom will be examined. Secondly, a D-L model will be employed to represent the stick-slip phenomena for deep oil well drilling. 


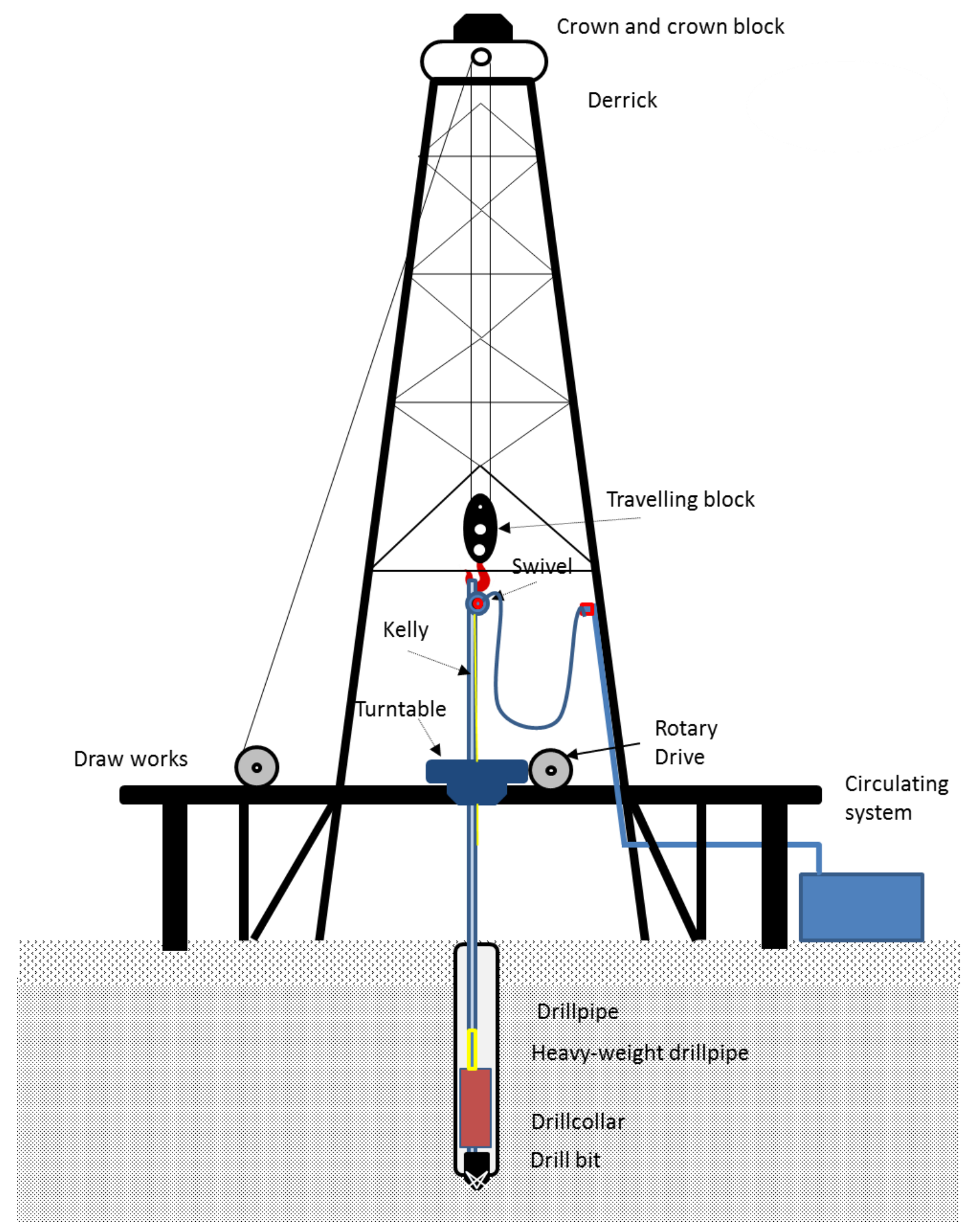

Figure 1 A vertical oil drilling system 


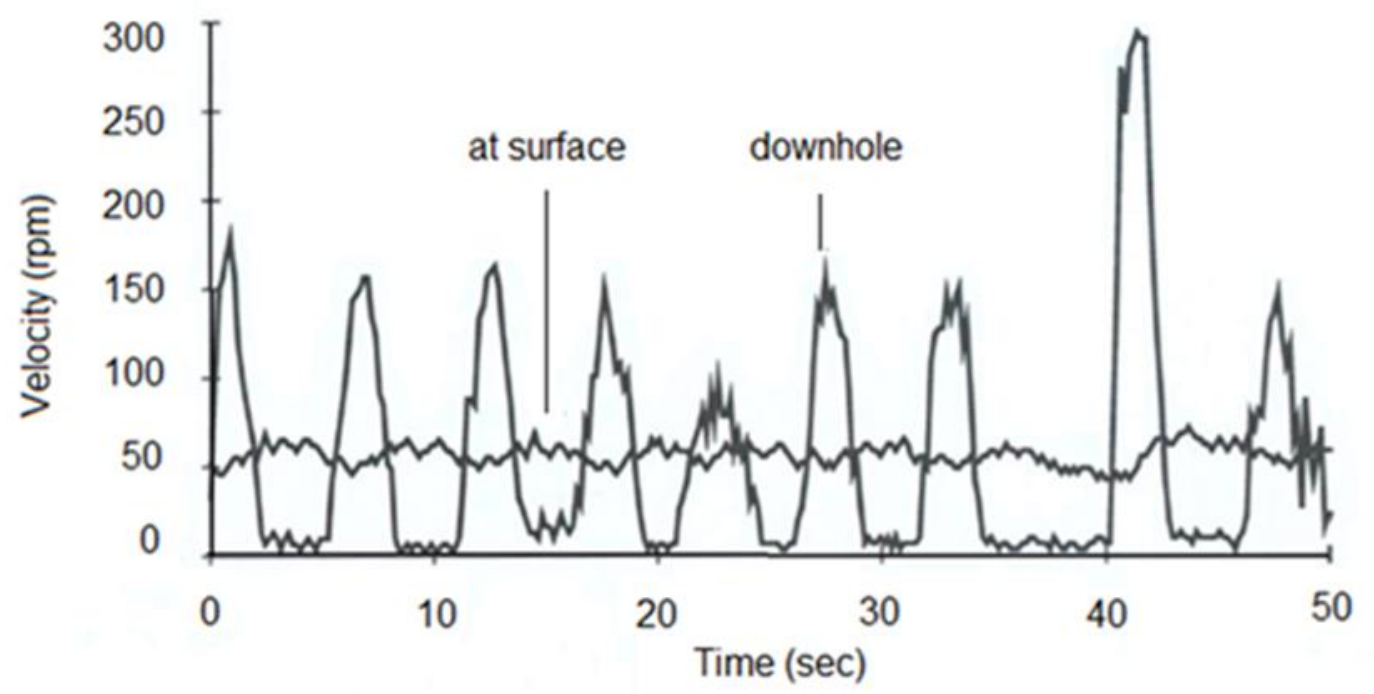

Figure 2 Stick-slip oscillation(5)

\section{2- Lumped Model.}

For an understanding of stick-slip oscillations, a mathematical model of the drill string is necessary. This model can also be used to study the modes of vibration, the drill bit-rock interactions and to develop and test vibration damping equipment (11).

The problem of stick-slip vibration in oil drilling operations is often considered using a multiple, lumped-parameter, or finite element models, of the drill string (11-14). In this paper the drill string will be considered as a torsional pendulum with two degrees of freedom, driven by an electric motor, as shown in Fig. (3). The drill pipes are represented as a torsional spring with a stiffness coefficient $\left(K_{d p}\right)$ with torsional damping $\left(C_{d p}\right)$, due to the drill mud with structural damping and friction between the drill pipe and wellbore(15). From Figure 3, the governing equations are:

$$
J_{m s} \ddot{\theta_{r t}}+C_{m s} \dot{\theta_{r t}}+K_{d p}\left(\theta_{r t}-\theta_{b}\right)+C_{d p}\left(\dot{\theta_{r t}}-\dot{\theta_{b}}\right)=n T_{m} \quad 1
$$

and:

$$
J_{d s} \ddot{\theta_{b}}+C_{d s} \dot{\theta_{b}}-K_{d p}\left(\theta_{r t}-\theta_{b}\right)-C_{d p}\left(\dot{\theta_{r t}}-\dot{\theta_{b}}\right)=-T_{f b}
$$


where $J_{m s}$ represent the equivalent inertia comprising the rotary table $\left(J_{r t}\right)$, electric motor $\left(J_{m}\right)$ and transmission gearbox. $J_{d s}$ is the corresponding drill collar inertia $J_{d c}$, the heavy-weight drill pipe inertia (HWDP) $J_{h d p}$ and the third drill pipes inertia $J_{d p}(15)$. The coefficients $C_{m s}$ and $C_{e b}$ represent the equivalent viscous damping of the rotary table and $\mathrm{BHA}$, respectively. The torsional stiffness of the drill pipe is $K_{d p}$. The drill collar and HWDP are considered as a rigid body and $T_{f b}$ is a non-linear frictional torque along the BHA. The inertias of $J_{m s}, J_{d s}$ and $K_{d p}$ can be calculated as follows:

$$
\begin{aligned}
& J_{m s} \ddot{\theta}_{r t}=J_{r t} \ddot{\theta}_{r t}+n J_{m} \ddot{\theta}_{m}=J_{r t} \ddot{\theta}_{r t}+n J_{m} n \ddot{\theta}_{r t}=\left(J_{r t}+n^{2} J_{m}\right) \ddot{\theta}_{r t} \quad 3 \\
& J_{d s}=J_{d c}+\frac{1}{3} J_{d p}+J_{h d p} \quad 4 \\
& K_{d p}=\frac{G_{s}}{3 l_{d p}} \frac{\pi}{32}\left(d_{o, d p}^{4}-d_{i, d p}^{4}\right) \quad 5
\end{aligned}
$$

where $G_{s}$ is the shear modulus for steel, $l_{d p}=$ length of the drill pipe and $d_{o, d p}, d_{i, d p}$ are the outer and inner diameters of the drill pipe respectively.

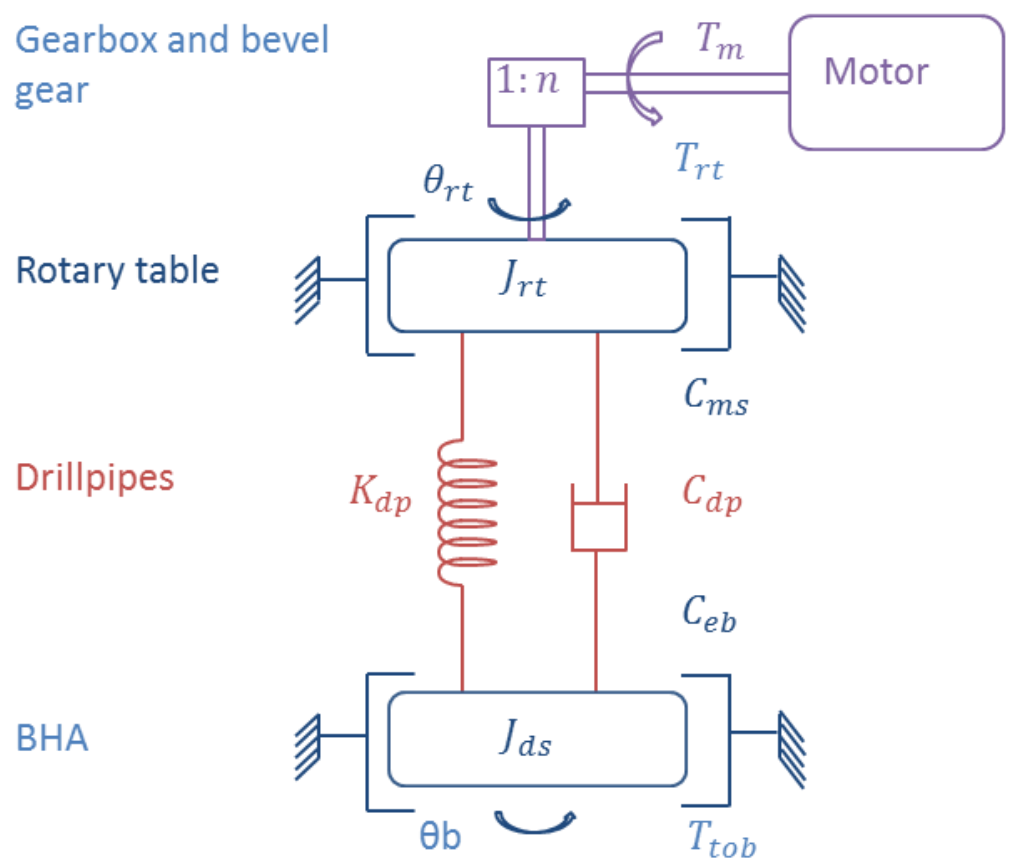

Figure 3 Representation of a drilling string as a torsional pendulum with two degrees of freedom 


\section{The model of frictional torque $\left(\boldsymbol{T}_{\boldsymbol{f b}}\left(\dot{\boldsymbol{\theta}_{b}}\right)\right)$}

The stick-slip vibrations in the well drilling shaft are driven by a nonlinear reactive torque which is combined with a viscous damping torque $\left(T_{v b}\right)$ due to the drill fluid and a friction torque $\left(T_{f b}\left(\dot{\theta_{b}}\right)\right)$, due to drill bit-rock contact. The friction torque depends on a wide range of factors, for example the types or rock, the drill bit type and the applied vertical force (16). Therefore the function representing the friction torque is bore- well dependent.

Since the friction resistance torque on the drill bit is directly proportional to WOB, the coefficient of friction and the radius of the drill bit can be written as:

$$
T_{f b}=W_{O b} R_{b} \mu_{b}\left(\dot{\theta}_{b}\right)
$$

where $W_{O b}$, is the weight on the drill bit (WOB). This is related to the' hook-on-load" applied at the surface, $R_{b}$ is the radius of the drill bit and $\mu_{b}\left(\dot{\theta}_{b}\right)$ is the friction coefficient of the drill bit which is speed dependent. There are also static and dynamic frictional forces represented by discontinuous, differential equations which are difficult to model with accuracy (17).

Many methods are used for modelling the frictional torque on the drill bit; Most of these models use a decreasing and continuous differentiable velocity when the velocity of the BHA is not equal to zero and is discontinuous, Otherwise, owing to the presence of coulomb friction, Navarro-Lopez and Suarez(2) use a dry friction model together with a Stribeck effect to model the friction torque on the drill bit (18). The dry friction model, when the $T_{f b}$ is multi-valued at $\dot{\theta}_{b}=0$ may be approximated by a combination of the model proposed by Leine $(19,20)$ and Karnopp (21), with a zero velocity band, as shown in equation 7 .

$T_{f b}\left(\dot{\theta_{b}}\right)= \begin{cases}T_{a b} & \text { if }\left|\dot{\theta}_{b}\right|<\Delta \omega T_{a b} \leq T_{s b} \text { stick } \\ T_{s b} \operatorname{sign}\left(T_{a b}\right) & \text { if }\left|\dot{\theta}_{b}\right|<\Delta \omega T_{a b}>T_{s b} \text { stick to slip transition } \quad 7 \\ T_{c b} \operatorname{sign}\left(\dot{\theta}_{b}\right) & \text { if }\left|\dot{\theta}_{b}\right|>\Delta \omega\end{cases}$ 
where $T_{a b}$ represents the external torque applied to the drill string which must overcome the static friction reactive torque $T_{s b}$, to rotate the drill bit.

$$
T_{a b}=\left(T_{t p}+T_{v p}\right)-T_{v b}=K_{d p}\left(\theta_{r t}-\theta_{b}\right)+C_{d p}\left(\dot{\theta}_{r t}-\dot{\theta}_{b}\right)-C_{\mathrm{eb}} \dot{\theta}_{b} \quad 8
$$

In equation 7, $T_{s b}$ is the static friction torque associated with $J_{\mathrm{ds}}\left(T_{s b}=R_{b} W_{O b} \mu_{s b}\right), T_{c b}$ is the sliding friction torque (cutting torque), $T_{c b}=R_{b} W_{O b} \mu_{b}\left(\dot{\theta}_{b}\right), \delta \omega>0$ where a limit velocity interval specifies a small neighborhood of $\dot{\theta}_{b}=0, \mu_{c b}$ and $\mu_{s b}$, are the coulomb and static friction coefficients associated with $J_{d s}$ and $\mu_{b}$ is the velocity-dependant dry friction coefficient, respectively,

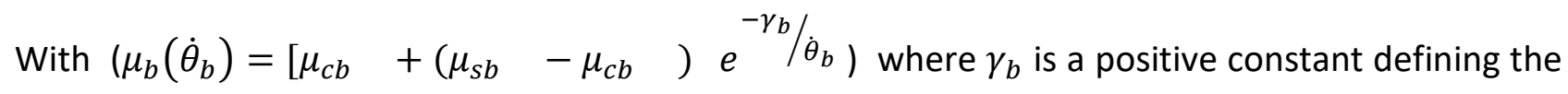
decaying velocity of $T_{f b}$, the resulting friction model is represented in Fig. 4 and can be compared with a classical dry friction model with an exponential- decaying law during the sliding phase.

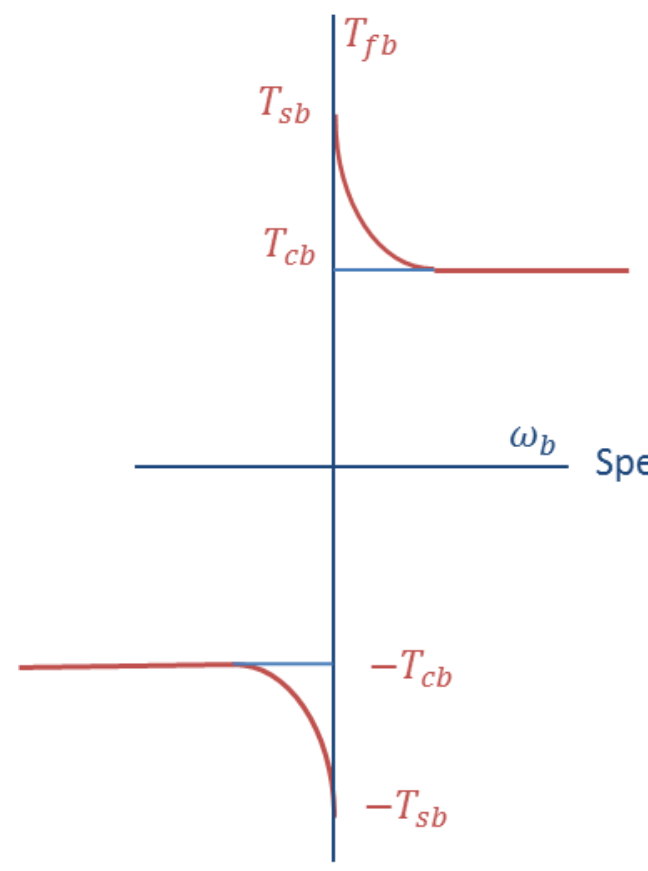

(1)

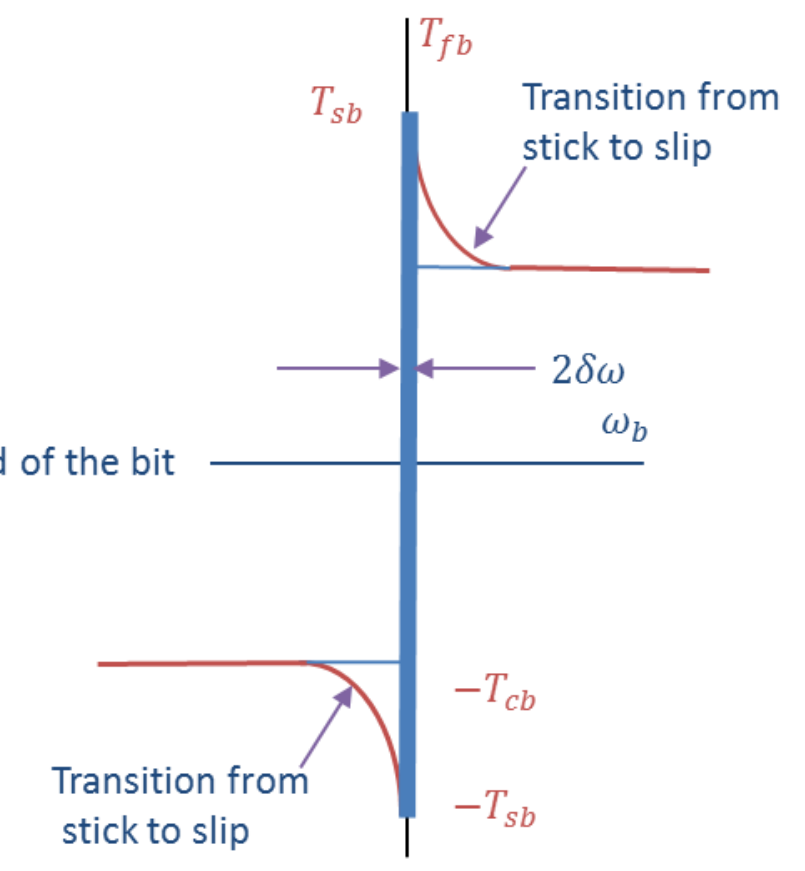

(2)

Figure 4 Friction torque at the drill bit: (1) dry friction with exponentialdecaying law at the sliding phase; (2) switch, friction model with a variation of Karnopp's friction model

From equations (1-8) the overall lumped model of the drill string for the purposes of simulation can be shown as in Figure 5. 


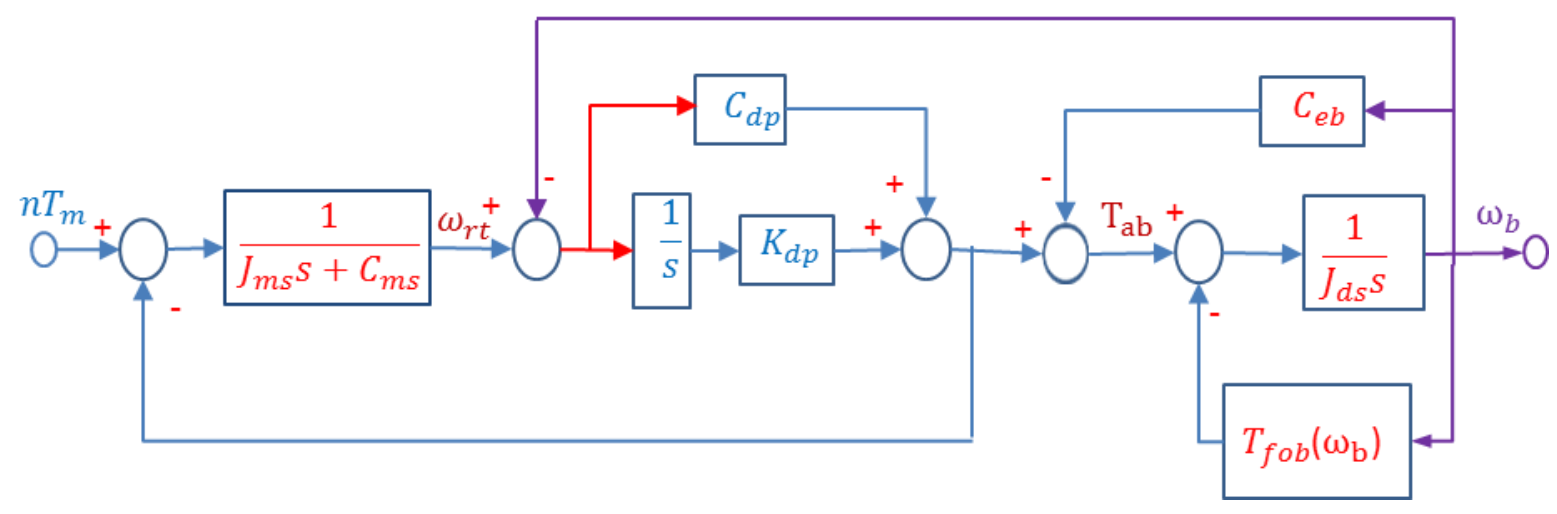

Figure 5 Block diagram of Drill string (lumped model)

\section{Distributed-Lumped System Approach}

A natural and more accurate procedure for the determination of the performance of a distributed dynamic system is by representing the actual system as a hybrid, distributed-lumped model. Whalley $(22,23)$ introduced a Hybrid Model comprising cascaded distributed parameter, dynamical elements separated by lumped parameter elements. Each of the distributed parameter elements will be assumed to have inputs such as force, voltage, pressure, etc. and outputs such as deflection, current, flow rate, etc. The output of each section represents the input of the following section. A series of alternating distributed and lumped sections are terminating with a lumped element can be incorporated.

According to Whalley (22), the energy dissipation throughout the system occurs in the lumped element due to entry, exit and reaction losses. One of the examples of the transmission system is the torsional distributed shaft when the torque is transmitted from the input to the output. The general equation of distributed shaft can be derived for a distributed shaft. Consider a segment of shaft length $\Delta \mathrm{x}$ at a distance $\mathrm{x}$ from the beginning of the shaft as shown in Figure $6(6),(24)$. 


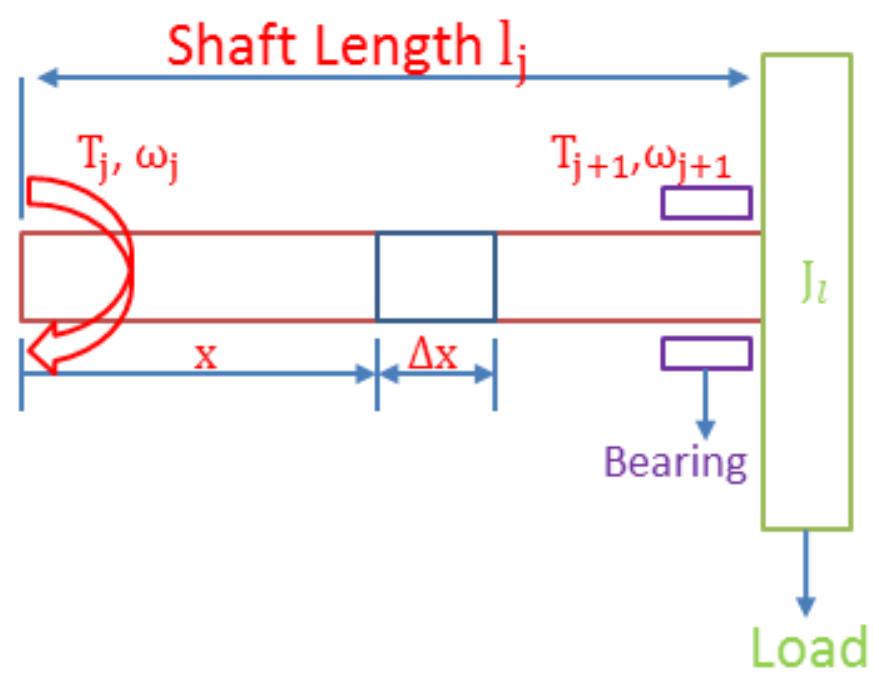

Figure 6 A Simple Torsional Shaft

The relation between the shear strain $(\gamma)$ and angle of twist of an element of length $\Delta \mathrm{x}$ is:

$$
\gamma=\frac{\mathrm{r} \partial \theta(\mathrm{x}, \mathrm{t})}{\partial \mathrm{x}}
$$

where $\theta$ Is the angle of twist, $\gamma$ Is the shear strain

From Hooke's law

$$
\begin{aligned}
& \mathrm{G}=\frac{\tau}{\gamma}=\frac{\mathrm{Tr} / \mathrm{J}}{\mathrm{r} \partial \theta(\mathrm{x}, \mathrm{t}) / \partial \mathrm{x}} \\
& \mathrm{T}=\mathrm{GJ} \frac{\partial \theta(\mathrm{x}, \mathrm{t})}{\partial \mathrm{x}}
\end{aligned}
$$

where: $G$ is the shear modulus of rigidity, J Is the shaft polar moment of inertia $\frac{\pi}{32} d^{4}$. The inertia torque acting on an element of length $\Delta \mathrm{x}$ is

$$
\mathrm{J} \rho \frac{\partial 2 \theta}{\partial \mathrm{t}^{2}} \Delta \mathrm{x}
$$

where $\rho$ Is the density of the shaft $\left(\mathrm{kg} / \mathrm{m}^{3}\right)$, J $\rho$ Is the mass polar moment of inertia of the shaft per unit length (kg.m)

From Newton's second law

$$
\sum T=(J \ddot{\theta})
$$


The equation of motion can be expressed as:

$$
(\mathrm{T}(\mathrm{x}, \mathrm{t})+\Delta \mathrm{T}(\mathrm{x}+\Delta \mathrm{x}, \mathrm{t}))--T(x, t)=-J \rho \frac{\partial 2 \theta}{\partial t^{2}} \Delta x
$$

Divided on $\Delta \mathrm{x}$ and take (limit $\Delta \mathrm{x} \rightarrow 0$ )

$$
\frac{\partial \mathrm{T}(\mathrm{x}, \mathrm{t})}{\partial \mathrm{x}}=-\mathrm{J} \rho \frac{\partial^{2} \theta(\mathrm{x}, \mathrm{t})}{\partial \mathrm{t}^{2}}
$$

Derive equation 10 with respect to $t$ :

$$
\frac{\partial T(x, t)}{\partial t}=-G J \frac{\partial^{2} \theta(x, t)}{\partial x \partial t}
$$

Expressing:

$$
\omega(x, t)=\frac{\partial \theta(x, t)}{\partial t}
$$

Equation 13 and 14 can be written as:

$$
\begin{aligned}
& \frac{\partial \mathrm{T}(\mathrm{x}, \mathrm{t})}{\partial \mathrm{x}}=-\mathrm{J} \rho \frac{\partial \omega(\mathrm{x}, \mathrm{t})}{\partial \mathrm{t}} \\
& \frac{\partial \omega(\mathrm{x}, \mathrm{t})}{\partial \mathrm{x}}=-\frac{1}{\mathrm{GJ}} \frac{\partial \mathrm{T}(\mathrm{x}, \mathrm{t})}{\partial \mathrm{t}}
\end{aligned}
$$

$\mathrm{L}=\mathrm{J} \rho$ and $\mathrm{C}=\frac{1}{\mathrm{GJ}}, \frac{1}{\mathrm{GJ}}$ is the Compliance per unit length and $\mathrm{J} \rho$ is the shaft inertia per unit length

Also, the characteristic impedance and propagation constant of the shaft are:

$\xi=\sqrt{\frac{L}{C}}=J \sqrt{G \rho}$

$\Gamma=s \sqrt{C L}=s \sqrt{\rho / G}$ 20

Using the solution given in Whally and A-Ameer(25) it follows that the equation of the torsional system of Figure 6 can be expressed as: 


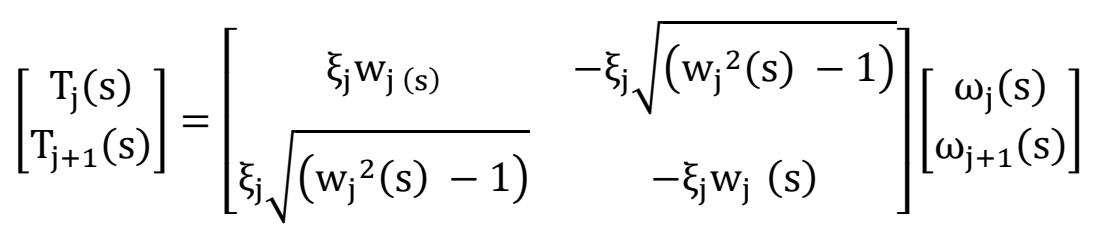

where

$$
W_{j}(s)=\frac{e^{2 \Gamma_{j} l_{j}}+1}{e^{2 \Gamma_{j} l_{j}}-1}
$$

\section{5-Distributed-Lumped Model of Drill string}

In this section, the concept of the lossless transmission line will be used to derive the $D-L$ model of the drilling system in terms of the general equation for a torsional distributed shaft (Eq. 21). First, the whole drilling system can be represented as a drive system comprises of motor, gearbox, and turntable as the lumped model. The drill pipe has a characteristic impedance $\left(\xi_{d p}\right)$ and the bottom hole assemblies (BHA) and HWDP have an equivalent inertia $\left(U_{e b}\right)$ as shown in Figure 7.

Equation 21 for the distributed torsional shaft can be represented in matrix form as follows with $j=1$.

$$
\left[\begin{array}{c}
\mathrm{T}_{1, d p}(\mathrm{~s}) \\
\mathrm{T}_{2, d p}(\mathrm{~s})
\end{array}\right]=\left[\begin{array}{cc}
\xi_{1} \mathrm{w}_{1}(\mathrm{~s}) & -\xi_{1} \sqrt{\left(\mathrm{w}_{1}^{2}(\mathrm{~s})-1\right)} \\
\xi_{1} \sqrt{\left(\mathrm{w}_{1}{ }^{2}(\mathrm{~s})-1\right)} & -\xi_{1} \mathrm{w}_{1}(\mathrm{~s})
\end{array}\right]\left[\begin{array}{l}
\omega_{1}(\mathrm{~s}) \\
\omega_{2}(\mathrm{~s})
\end{array}\right] \quad 23
$$

where

$\mathrm{T}_{1, d p}(\mathrm{~s})$ Is the input torque to drill pipe from rotary table

$$
\mathrm{T}_{1, d p}(\mathrm{~s})=T_{r t}-\mathrm{J}_{m s} \mathrm{~s} \omega_{r t}(\mathrm{~s})-\mathrm{C}_{m s} \omega_{r t}(\mathrm{~s})
$$

$\mathrm{T}_{2, d p}(\mathrm{~s})$ Is the output torque from drill pipe to BHA.

$$
\mathrm{T}_{2, d p}(\mathrm{~s})=T_{f b}+\mathrm{J}_{d c} \mathrm{~s} \omega_{b}(\mathrm{~s})+\mathrm{C}_{e b} \omega_{b}(\mathrm{~s})
$$

$T_{f b}$ Is the friction torque on the drill bit as demonstrated in Eq. 4, but in D-L model the applied torque on the drill bit is

$$
\mathrm{T}_{a b, d}=T_{2, d p}-T_{v b}
$$

$\mathrm{J}_{e d}$ Is the equivalent mass moment inertia of drill collar and HWDP 


$$
J_{e d}=G_{s} \rho \frac{\pi}{32}\left[l_{c}\left(d_{o, c}^{4}-d_{i, c}^{4}\right)+l_{h}\left(d_{o, h}^{4}-d_{i, h}^{4}\right)\right]
$$

$\mathrm{C}_{e b}, \omega_{b}$, are the damping and angular velocity of drill collar and HWDP, $\xi_{1}$ Is the characteristic impedance of the drill pipe $\left(\xi_{1}=J_{d p} \sqrt{G_{s} \rho}\right), \mathrm{w}_{1(\mathrm{~s})}=\frac{\mathrm{e}^{2 \Gamma_{1} \mathrm{l}_{1}}+1}{\mathrm{e}^{2 \Gamma_{1} 1}-1}, \Gamma=\mathrm{s} \sqrt{\rho / G_{s}}$ is the propagation constant of the drill pipe, $l_{1}$ is equal to the length of drill $\left(l_{d p}\right)\left(\Gamma=\mathrm{s} \sqrt{\rho / G_{s}}, \quad \omega_{1}(\mathrm{~s})\right.$ Is the angular velocity at the inlet of the drill pipe and this is equal to the angular velocity of the rotary table $\left(\omega_{1}=\omega_{r t}\right) \cdot \omega_{2}(\mathrm{~s})$ Is the angular velocity at the outlet of drill pipe which is equal to the angular velocity of the drill collar $\left(\omega_{2}=\omega_{b}\right)$.

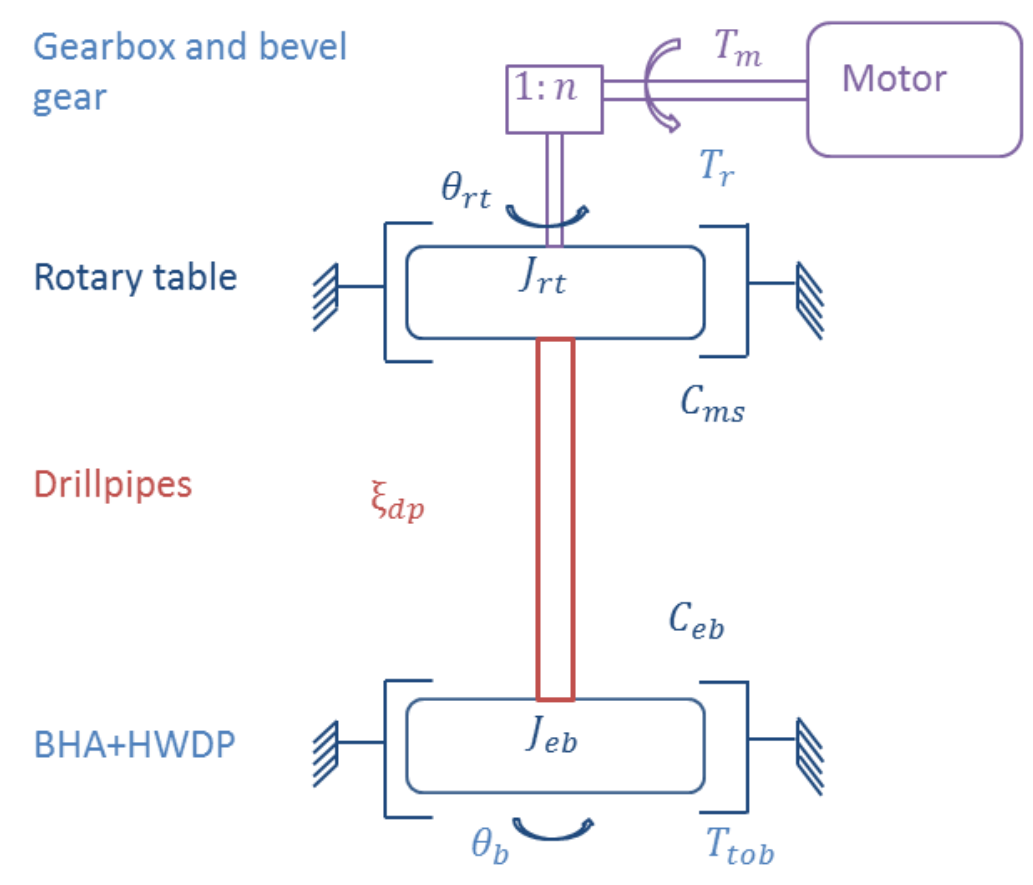

Figure 7 representation of a drilling system as a torsional transmission line driven by DC motor

From equation 23-26 the block diagram represents the drill string as a D-L model is shown in Figure 8. 


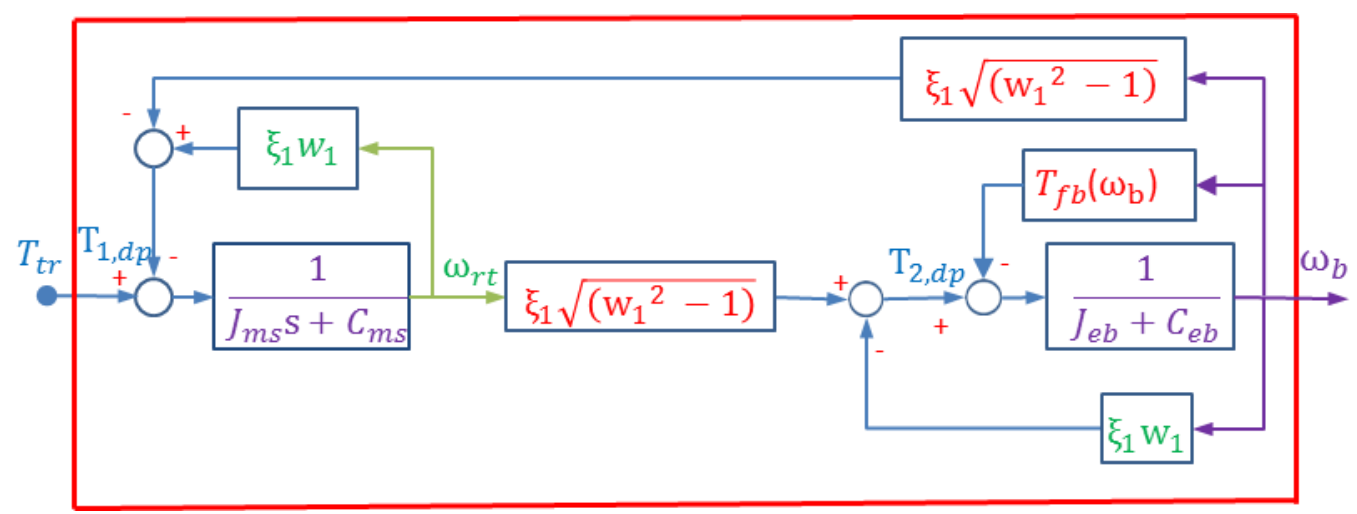

Figure 8 Block diagram representation Drill string as L-D model

\section{6-Comparison between D-L and $L$ model}

The purpose of modelling the stick-slip motion is to find the optimum way to suppress the vibration of the drilling operation in order to reduce damaging the drilling system and decrease the cost. In the drilling process, the range of speeds that are used for drilling is typical between 30 and $150 \mathrm{rpm}$ (26). However, the average speed in stick-slip vibration is $50 \mathrm{rpm}$. When there is no stick-slip vibration, this is approximately $120-125 \mathrm{rpm}$. Therefore, the comparison between the two modelling methods will cover this range of velocities in order to demonstrate the ability of each model to replicate, low and high-velocity drilling.

\subsection{Case Study One $\left(l_{d p}=500 m\right)$}

During the simulation of stick-slip motion using the D-L and $L$ models, there are many issues that play a significant role in describing this mechanism. One of the important items is the critical speed of the drilling system. Above this critical velocity there is no stick-slip whilst below this velocity stick-slip, vibration occurs. So the difference between the two models will be studied.

During drilling operations, the speed of drilling depends on the type of rock formation. If the rock is hard, the speed of drilling should be low and the weight on the drill bit should be high. The comparison between the two models will focus on the two main points relating the beginning of stick-slip motion and end when the angular velocity of the drilling is decreased from sliding mode towards the critical speed until quiescence. Secondly the difference between the two models at the desired speed of drilling of $\omega_{r t}=50 \mathrm{rpm}$. 
At the torque of rotary table is $14125 \mathrm{Nm}$ the D-L model with a speed of approx $133 \mathrm{rpm}$ and when the torque reduce under this value the stick-slip will appear in $D-L$ while the $L$ model remains in the ordinary mode, where there is no sticking. Therefore this value considered as the critical speed of D-L model. When the torque of rotary table reduce under to $13725 \mathrm{Nm}$ the stick-slip starts in the lumped model as well, at velocity of $125 \mathrm{rpm}$ which considered as the critical speed of L model, as shown in Figure 9.

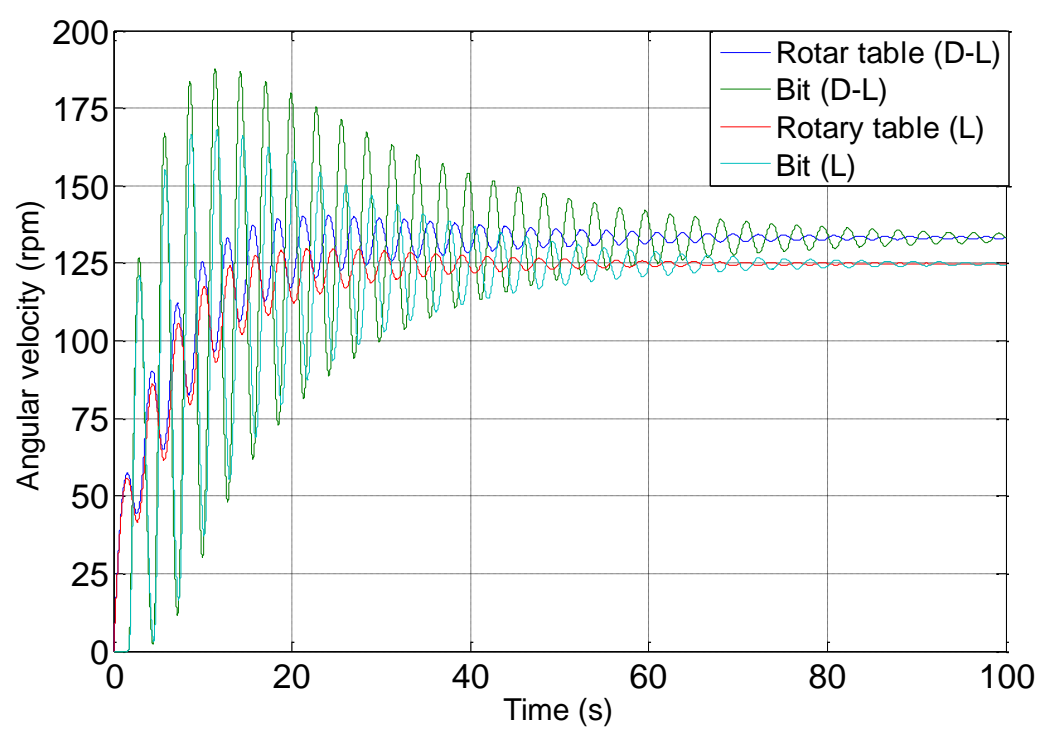

Figure 9 Comparison between the two models at critical speed (case 1)

When the torque on the rotary the table decreases to $9075 \mathrm{Nm}$ the lumped model shows the stick-slip vibration at a speed of $12.5 \mathrm{rpm}$, and by decreasing the torque to $900 \mathrm{Nm}$ the lumped model does not show the stick-slip while the distributed-lumped model showings stick-slip motion at very low speed of around 11 rpm, as in Figure 10. 


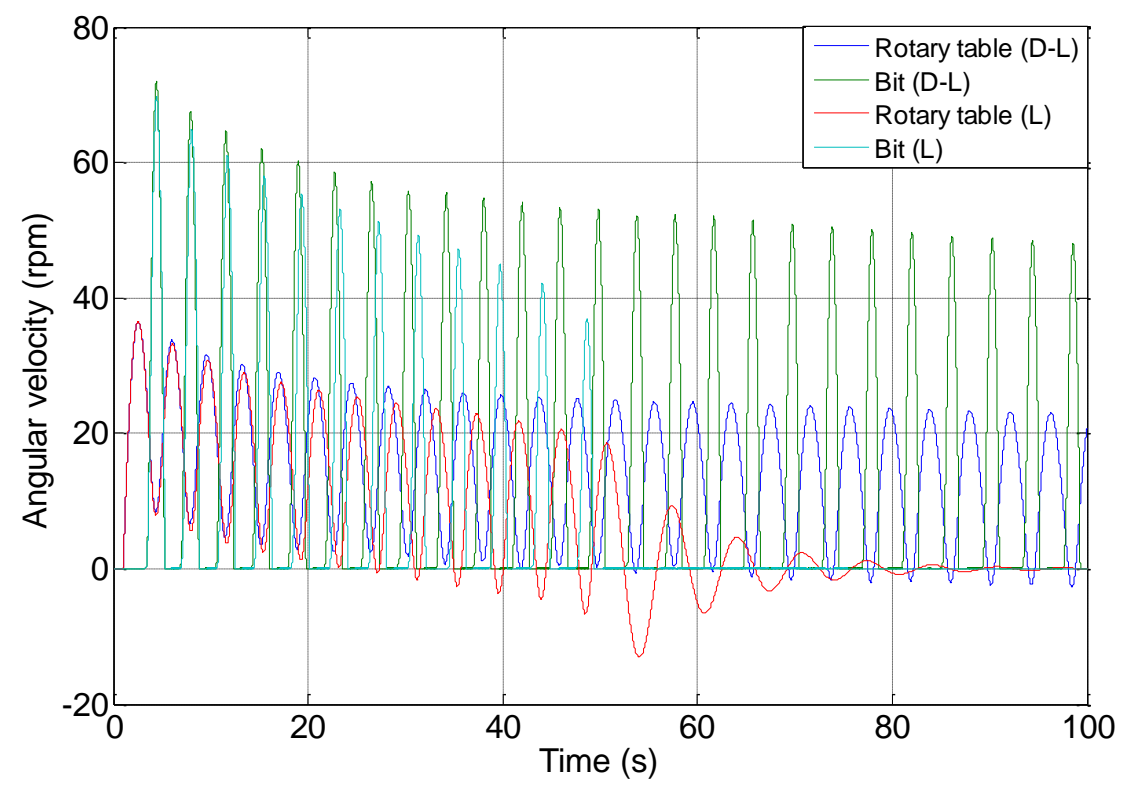

Figure 10 Comparison between the two models at minimum speed (case 1)

At the desired speed $(50 \mathrm{rpm})$ the general trend of D-L and lumped model are similar, as shown in Figure 11 when the average velocity exhibited by both models is equal to the desired operating speed.

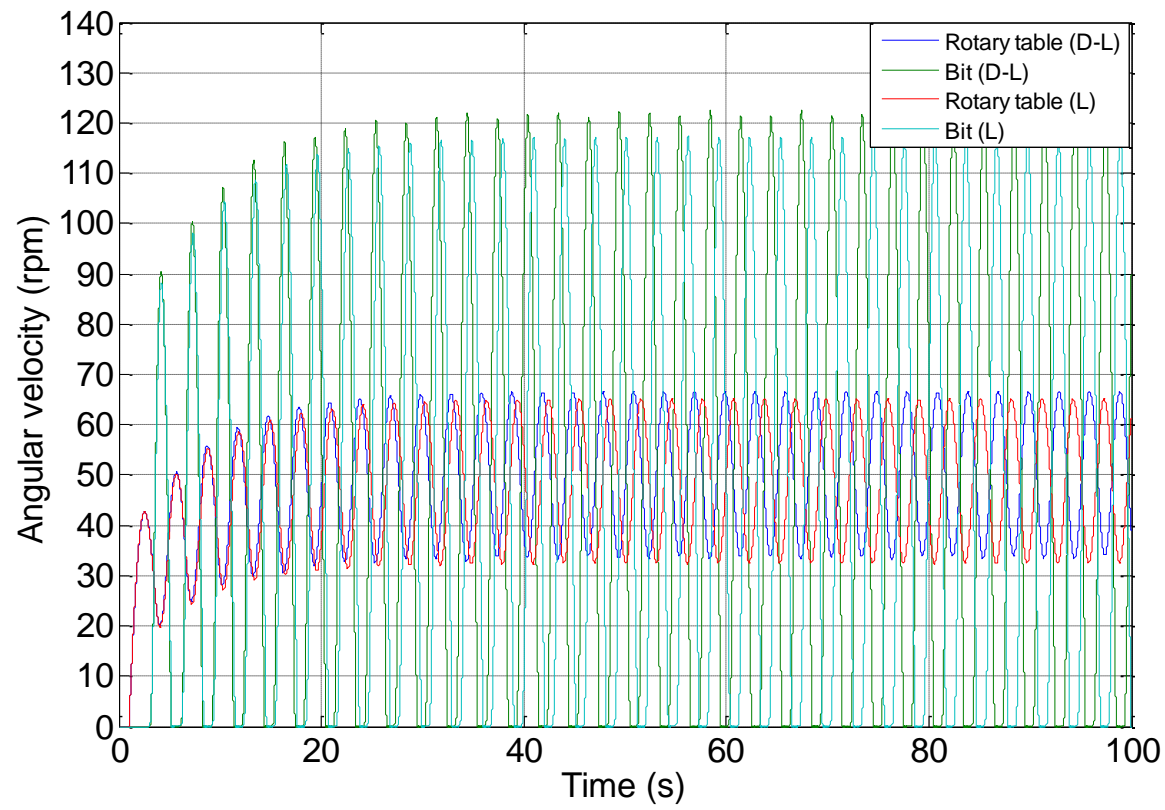

Figure 11 Comparison between the two models at speed $50 \mathrm{rpm}$ (case 1) 
To give complete insight regarding the applied load on the drill bit, two types of figures will be used as shown in Figure 12 and Figure 13, for both models. The first figure shows the variation in applied torque; the second figure demonstrates the change in applied torque with varying drill bit velocity. From these figures, the applied torque on the drill bit, for both models, is similar to the slight difference in the torque pattern.

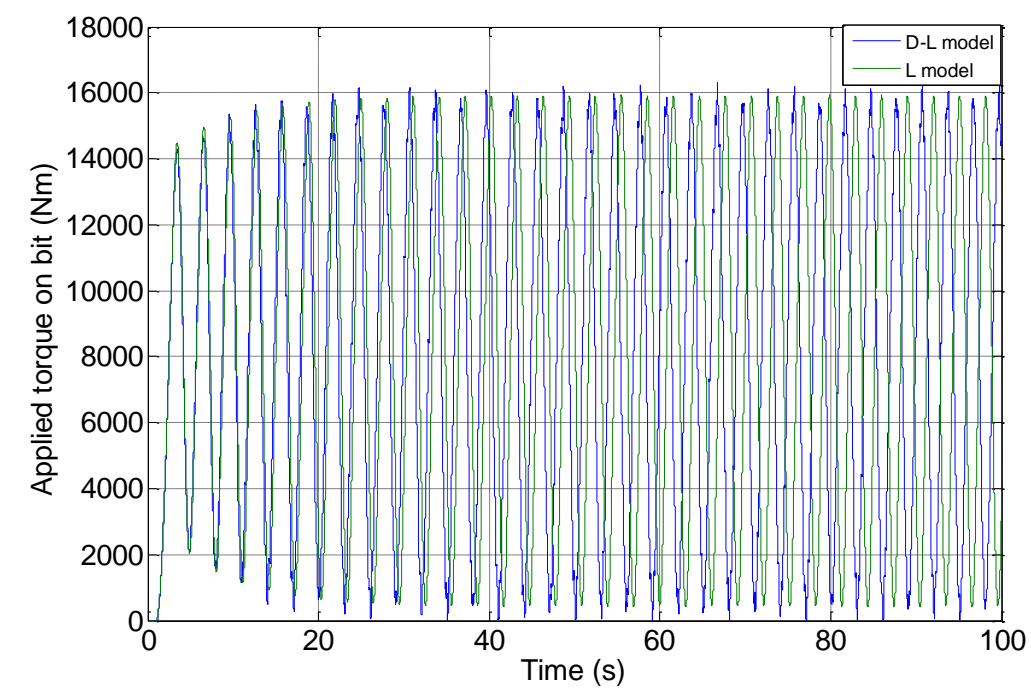

Figure 12 The applied torque on the drill bit at desired speed (torque verse time) (case 1)

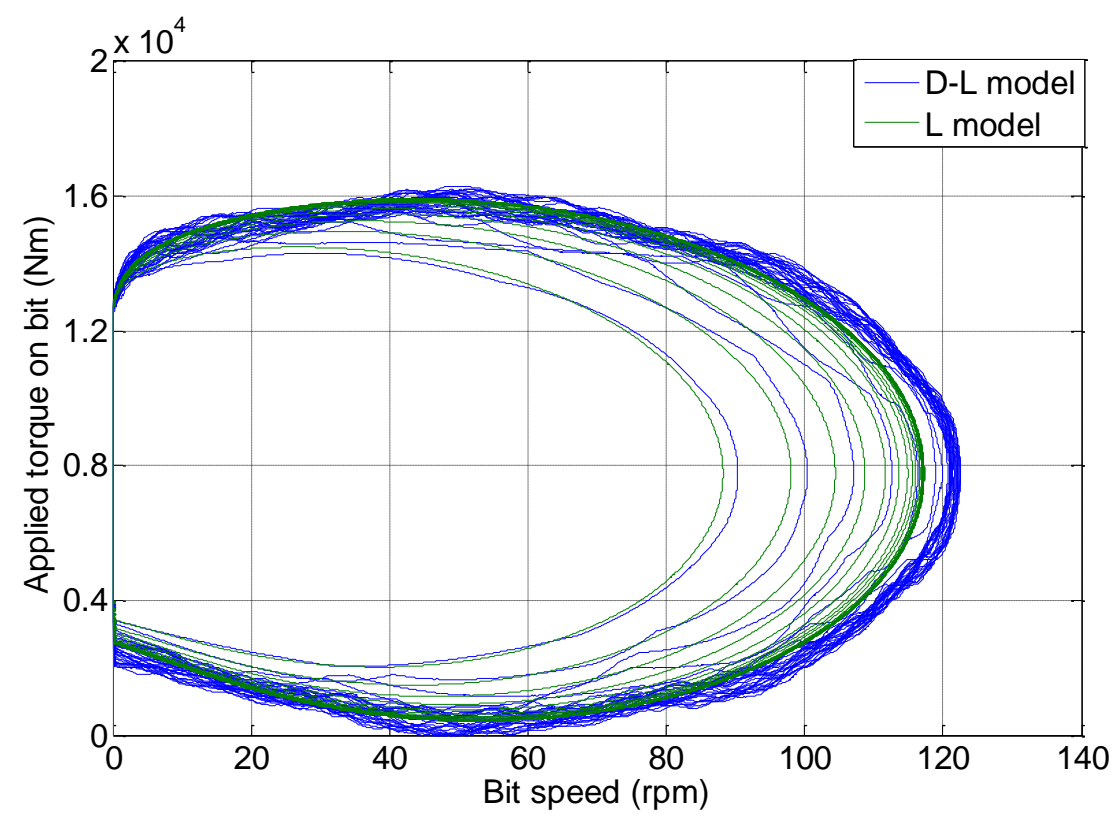

Figure 13 The applied torque on the drill bit at desired speed (torque verse speed) (case 1) 


\subsection{Case Study Two $\left(l_{d p}=2000 m\right)$}

From Figure 14 the critical speed of the D-L model is higher than the L model. The critical speed of the D-L model is about $123 \mathrm{rpm}$ when the torque of the rotary table is equal to $13900 \mathrm{Nm}$ while the critical speed of the $L$ model is approximately $100 \mathrm{rpm}$ where the torque on the rotary table is $12775 \mathrm{Nm}$.

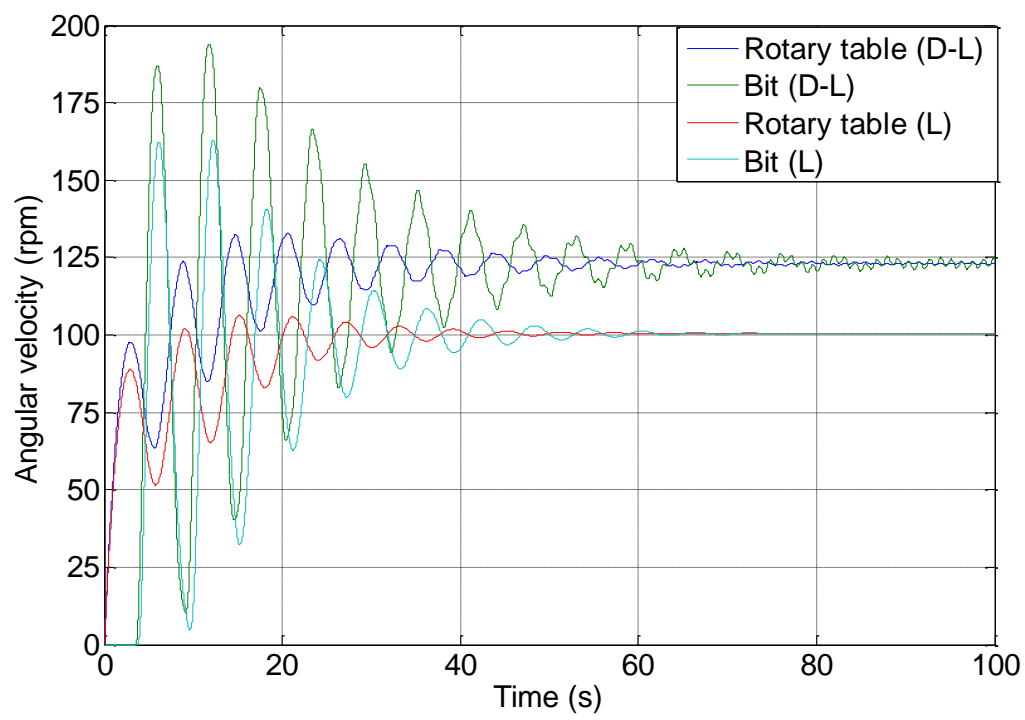

Figure 14 Comparison between the two models at critical speed (case 2)

From Figure 15 the distributed-lumped and lumped system shows the stick-slip, vibration at very low speed, of $32 \mathrm{rpm}$, for the lumped model with the torque of the rotary table equal to $9900 \mathrm{Nm}$. When the torque of the rotary table reaches $9350 \mathrm{Nm}$ the velocity of the lumped system becomes zero while the distributed-lumped model shows the stick-slip motion. At this value, the average velocity of the rotary table for the distributed-lumped model is approximately $15 \mathrm{rpm}$. 


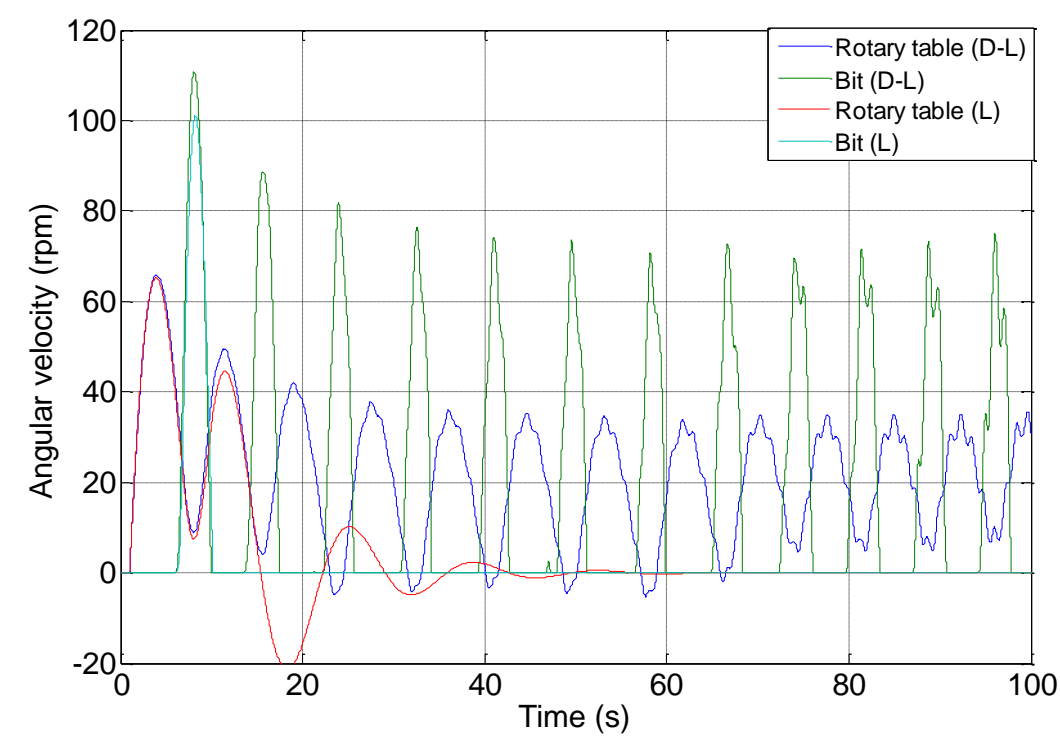

Figure 15 Comparison between the two models at minimum speed (case 2)

At the desired speed, the difference between the $D-L$ and $L$ model appears clearly and the angular velocity of both models is as shown in Figure 16. This difference increases with an increase in the simulation time until quiescence in both models. The main difference in both models can be summarized as follows.

- The angular velocity of the rotary table $\left(\omega_{r t}\right)$ for the $D-L$ model increase and decrease on a fluctuating curve in comparison with the $L$ model which has a smooth curve.

- The angular velocity of the drill bit in D-L model varies between zero and different upper values for example 120,130, 140 rpm, etc. while in L model between zero and fixed uppervalue $115 \mathrm{rpm}$.

- The number of stick-slip is not equal in both models.

- Increasing the difference in the steady state between the two models is as shown in Figure 17.

- The average value of the $D-L$ model is equal to the desired (50rpm) value while in the $L$ model equal to 40rpm

The applied torque on, the drill bit in the D-L model shows an irregular shape while the L model shows a regular shape. The difference between the two models is very clear when compared to the case study one as shown in Figure 18 and Figure 19. 
When comparing the two models in steady state with actual measurement, as shown in Figure 2 , it can be concluded that.

- The general trend of the angular velocity of the drill bit $\left(\omega_{b}\right)$, as shown in Figure 17 , of the D-L model is similar to the angular velocity measurement as shown in the in Figure 2, when the angular velocity changes between zero and different upper values, while the lumped model does not show this behaviour as it keeps the same shape following the stick-slip vibration.

- From the actual figure, the number of stick slips is 9 in actual measurement and it is equal to the D-L models while in the lumped model this number is reduced to 7.

- The table speed response is similar to the D-L model.

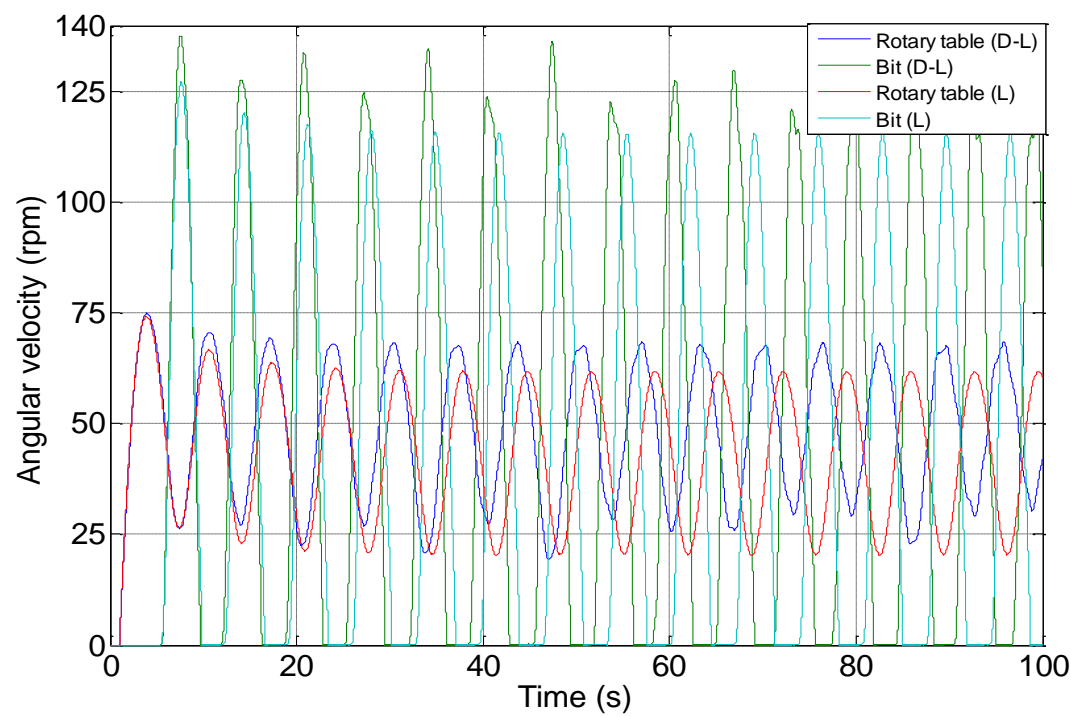

Figure 16 Comparison between the two models at speed $50 \mathrm{rpm}$ (case 2) 


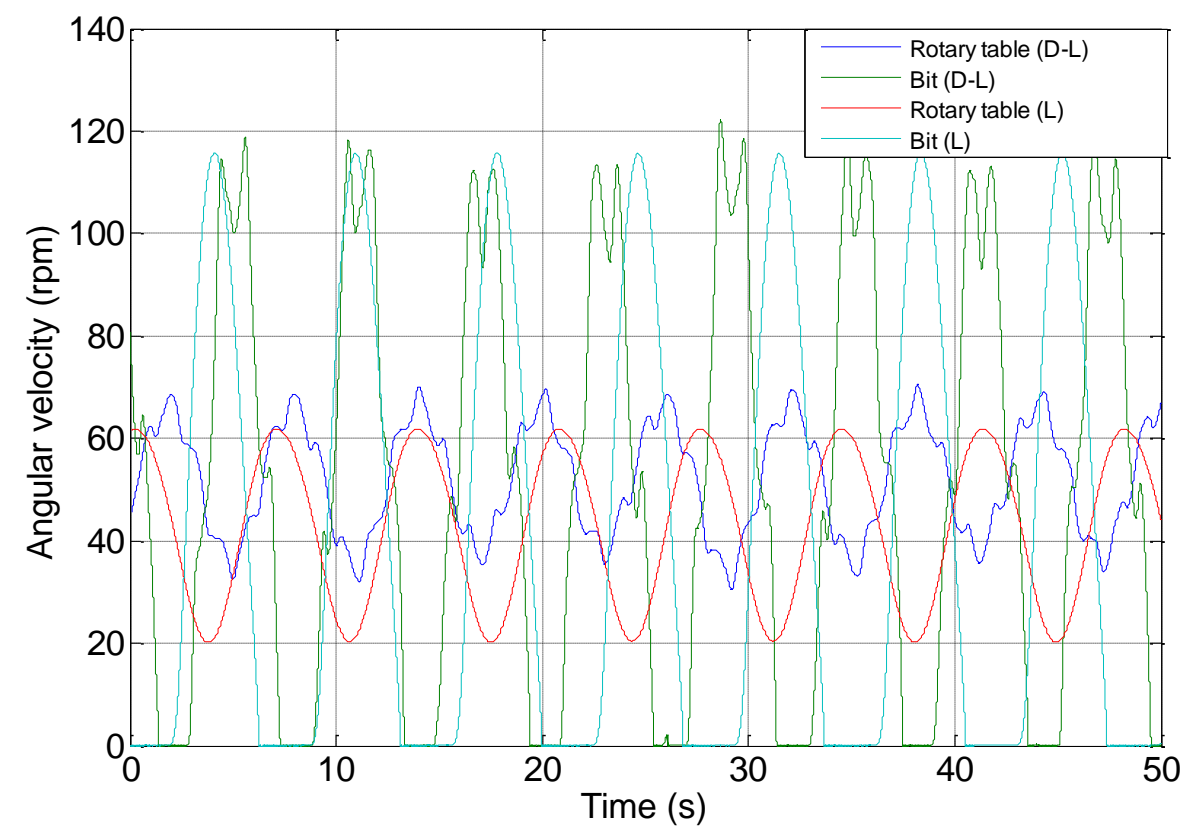

Figure 17 Comparison between the two models at speed 50rpm(steady state)

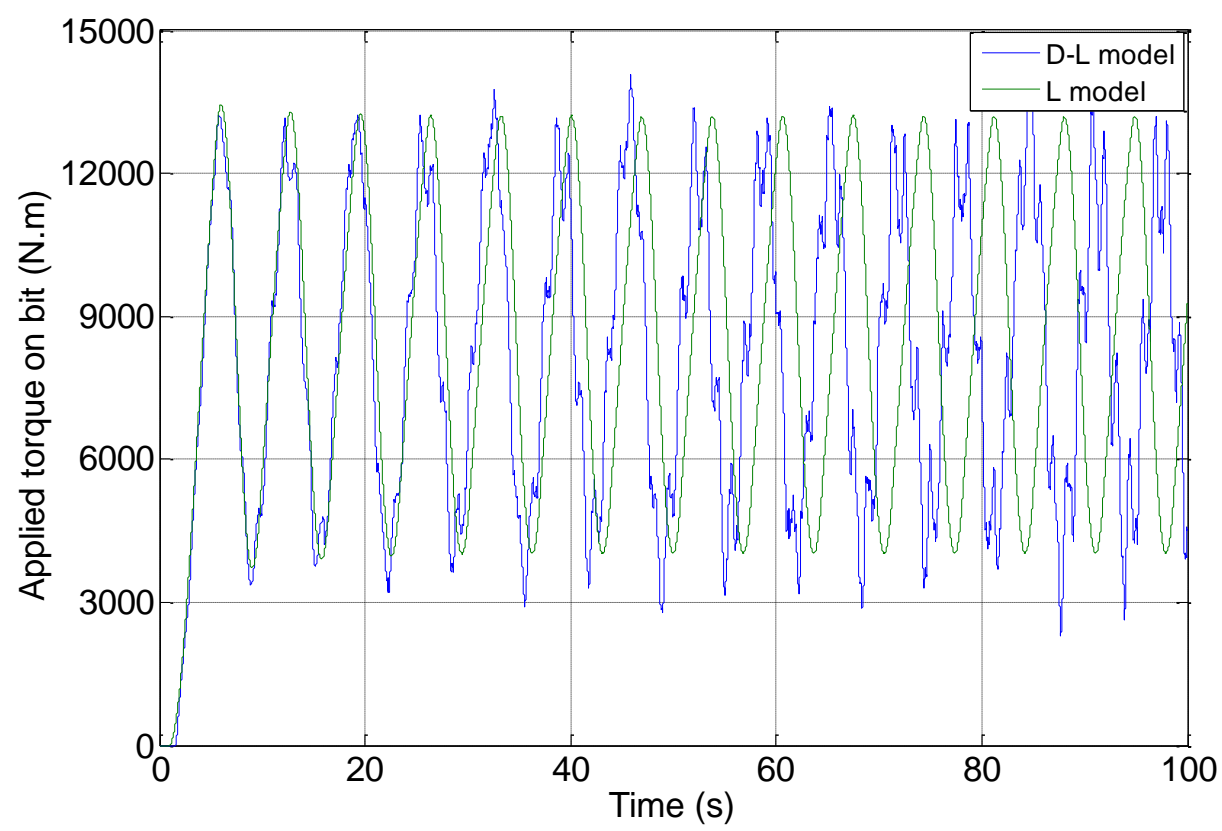

Figure 18 The applied torque on the drill bit at desired speed (torque verse time) (case 2) 


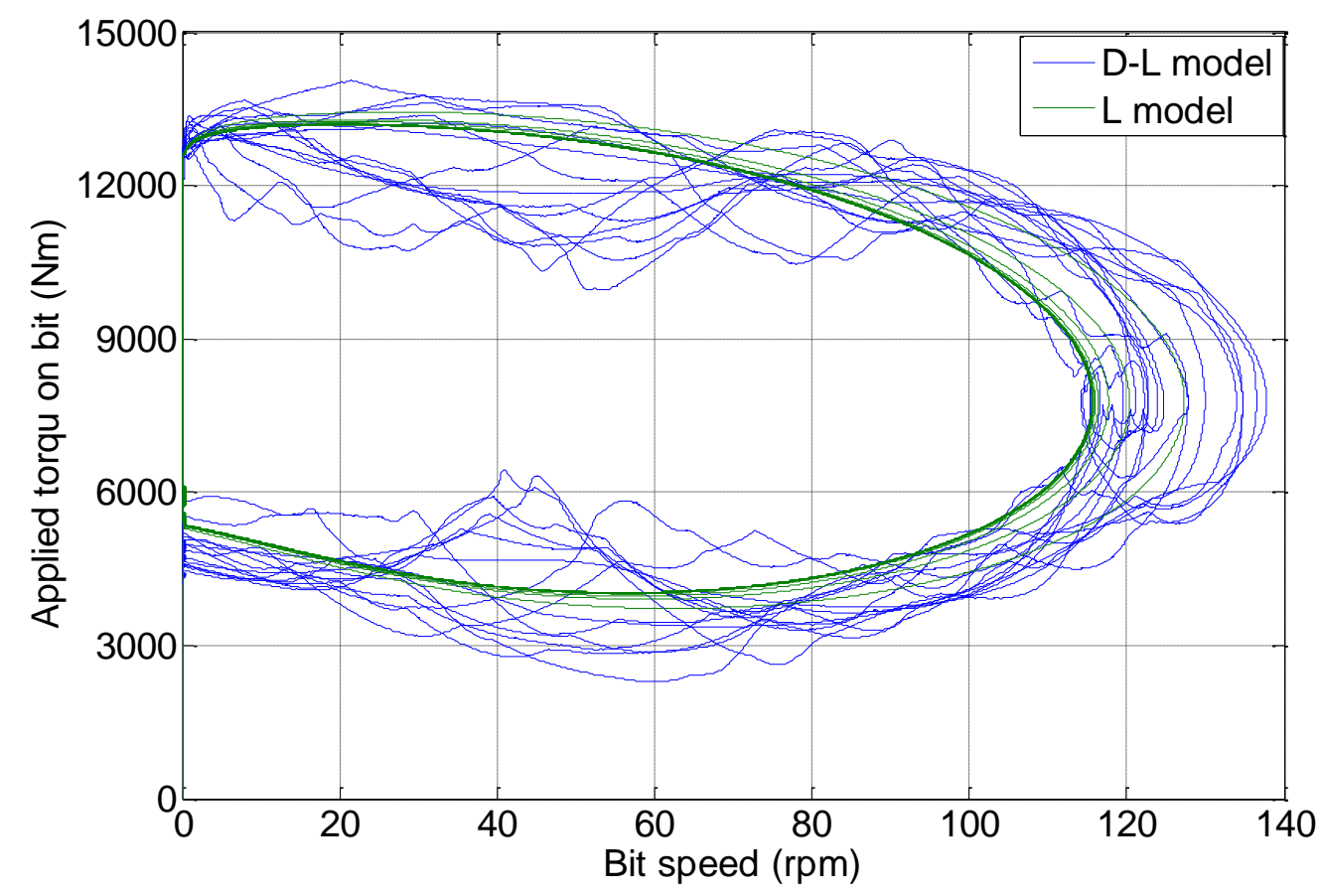

Figure 19 The applied torque on the drill bit at desired speed (torque verse speed) (case 2)

\subsection{Case Study Three $\left(l_{d p}=5700 m\right)$}

When the length of drill pipe is increased, there is a decrease in the torsional stiffness $\left(K_{d p}\right)$ of the drill pipe. Hence the stick-slip motion increases. From Figure 20 the D-L model shows that the critical speed happens at low table velocity of $81 \mathrm{rpm} T_{r}=10700 \mathrm{Nm}$ when the torque of the rotary table is $T_{r}=10700 \mathrm{Nm}$ while with the $\mathrm{L}$ model the critical speed is very low at approximately $50 \mathrm{rpm}$ and $T_{r}=9050 \mathrm{Nm}$. 


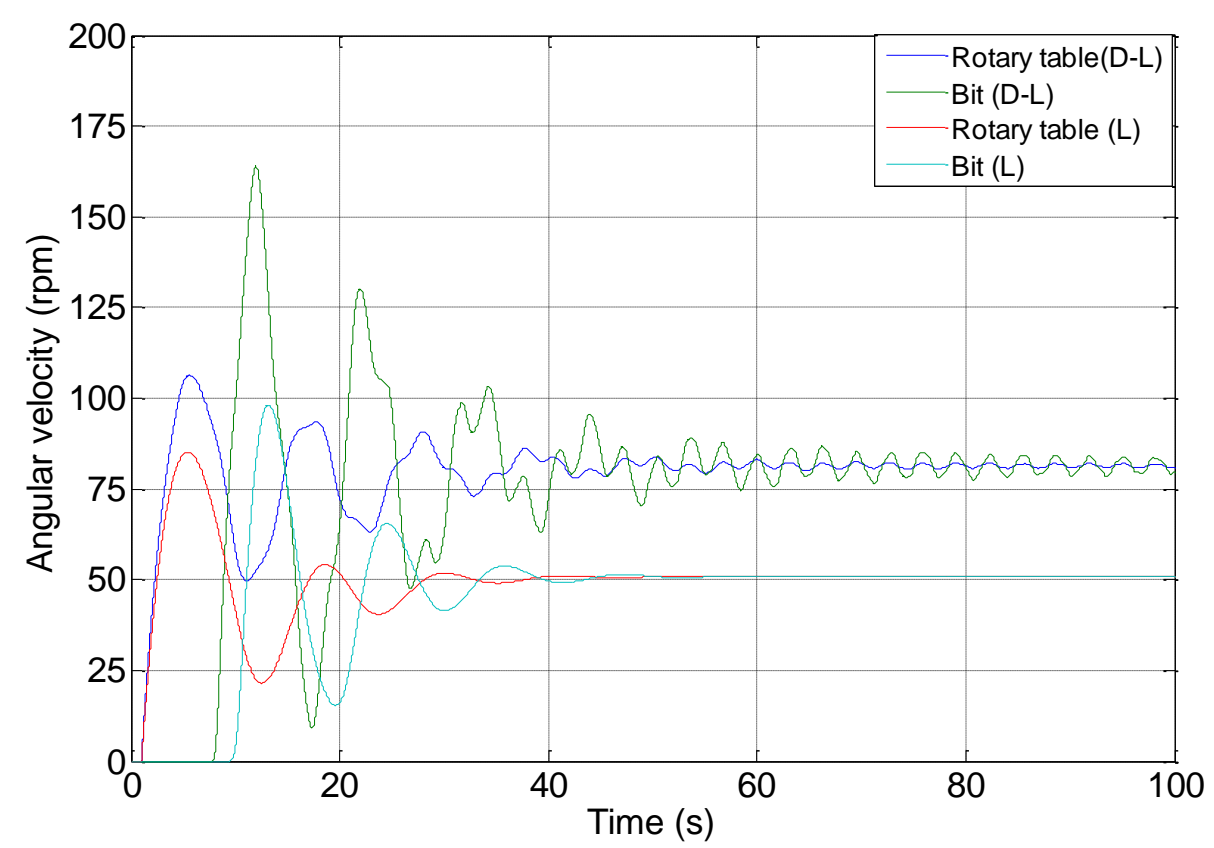

Figure 20 Comparison between the two models at critical speed (case 3)

With an increase in the depth of drilling to $5700 \mathrm{~m}$ the ability of the lumped model to show the stick-slip, vibration at this very low velocity decreases, where the maximum average velocity of the rotary table is around $30 \mathrm{rpm}$ with the torque $8950 \mathrm{Nm}$ while the ability of distributed-lumped model increases to show the stick-slip motion at an average velocity near to $\omega_{r t}=15 \mathrm{rpm}$ at a torque of $T_{r t}=7850 \mathrm{Nm}$, as shown in Figure 21 .

At the desired speed of the rotary table $(50 \mathrm{rpm})$ with torque of $T_{r}=92500 \mathrm{Nm}$ as shown in Figure 22 the stick slip does not occur in the lumped model and this is in conflict with experimental results(27) showing that stick-slip increases with increased drill pipe length. The fluctuating in angular velocity of the rotary table and drill bit for a distributed-lumped model increasing as shown in Figure 22. 


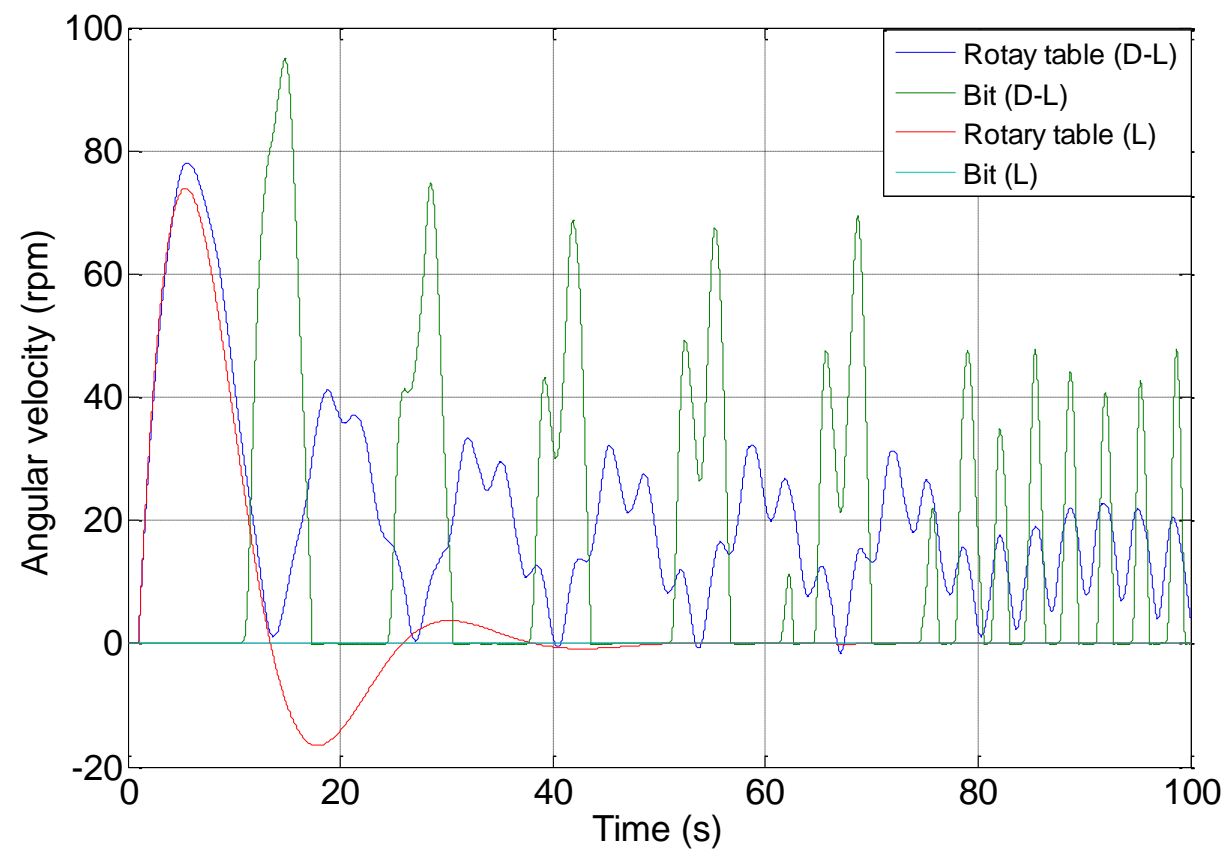

Figure 21 Comparison between the two models at minimum speed (case 2)

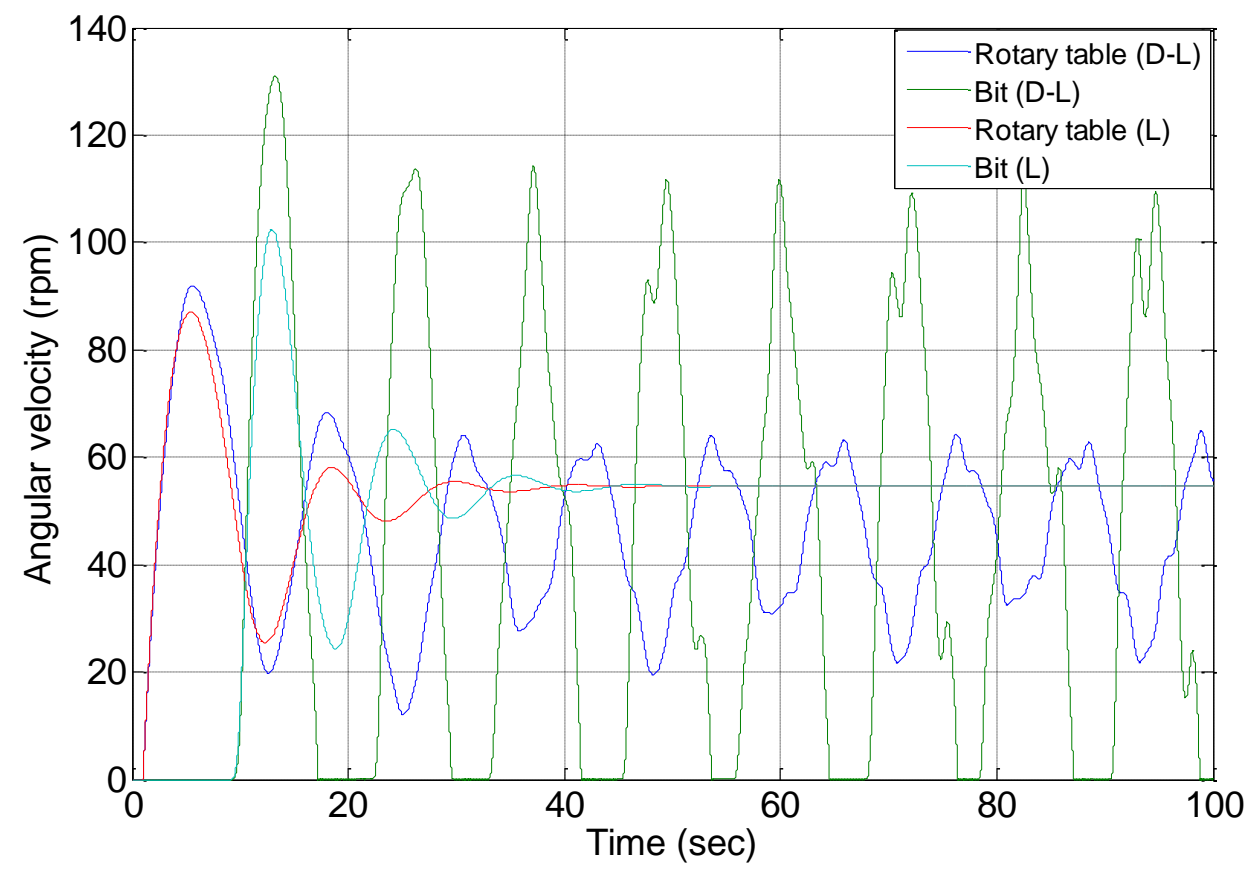

Figure 22 Comparison between the two models at desired speed (case 3)

The difference between the $\mathrm{D}-\mathrm{L}$ and $\mathrm{L}$ model with torque on the drill bit is very clear. Comparison of the cases of study 1 and 2 is shown in Figures 23 and 24. 


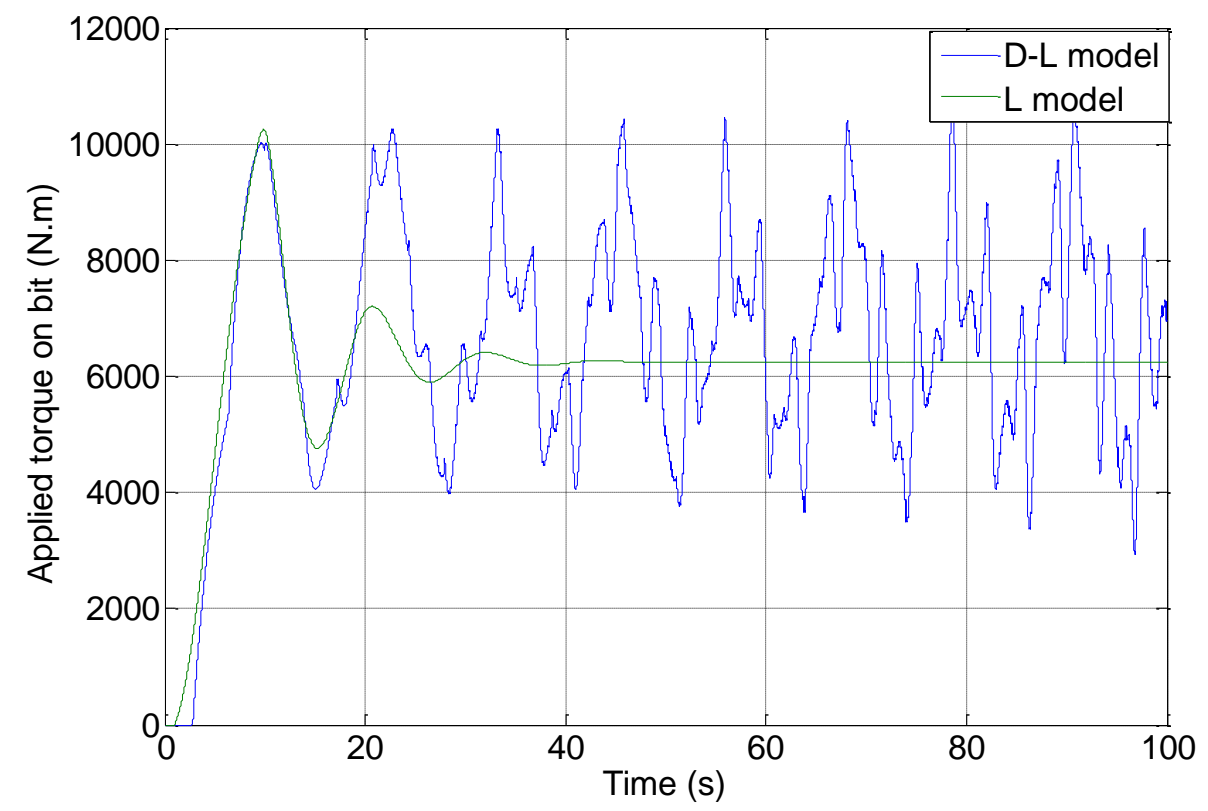

Figure 23 The applied torque on the drill bit at desired speed (torque verse time) (case 3) 


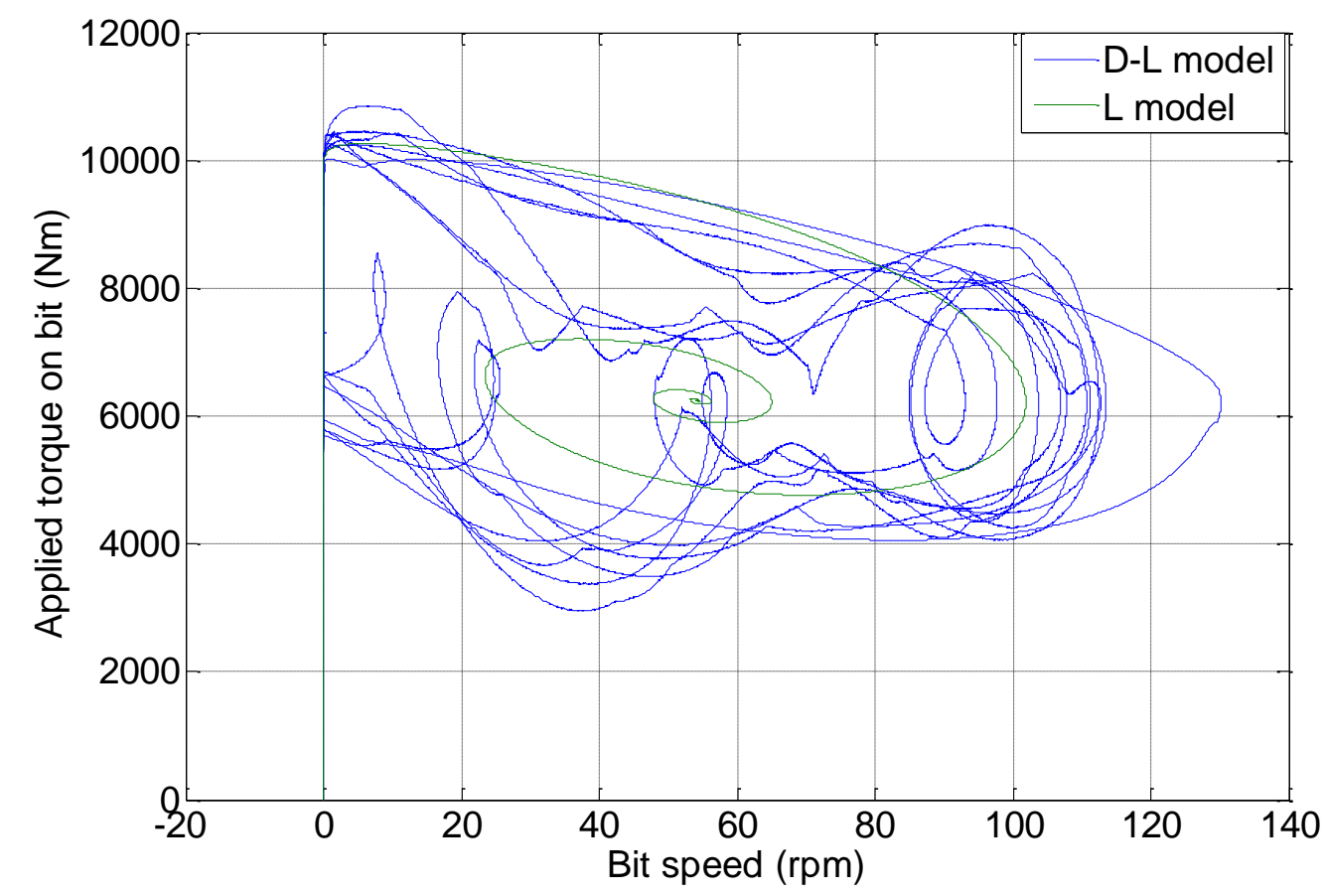

Figure 24 The applied torque on the drill bit at desired speed (torque verse speed) (case 3)

\section{7- Conclusions}

In this work, the distributed-lumped model and purely lumped model are used to model the drill string, stick-slip condition. The first step in this work is the comparison between the two models in order to use it for stick-slip vibration control.

From the comparison between the two models, in the three cases of study the following remarks can be drawn: 
1- The distributed-lumped model is found to be sensitive to the stick-slip, vibration and the critical speed at which this occurs. Below this value, stick-slip occurs in the distributedlumped model is always higher than the critical speed of lumped model.

2- The distributed-lumped models have the ability to show the stick-slip motion at low angular speeds with an average value of approx $\omega_{r t}=13 \mathrm{rpm}$ while the lumped model has this ability in short lengths of drill pipe $\omega_{r t}=13 \mathrm{rpm}$. With increased the length the ability to show the stick-slip vibration decreased.

3- Due to the importance of critical speed and it is very important to identify this value and the velocity at which sticks-slip starts. Therefore, the distributed-lumped model should be considered as a safe prospect than the lumped model in giving an indication of the velocity at which stick-slip vibrations start.

4- The angular velocity of the rotary table and drill bit in addition to the applied torque on the drill bit are identical in both models when the length of drill pipe equals $500 \mathrm{~m}$. The difference between the models appears clearly when the length of the drill pipe is $2000 \mathrm{~m}$ and this increases when the length reaches to $5700 \mathrm{~m}$.

5- From point 4 we can conclude that in a short length of drill pipe the lumped model or distributed-lumped model can be used for modelling stick-slip vibrations. However, the distributed-lumped is preferred because the critical speed still differs between the two models.

6- The intensity of vibration of lumped model is constant with increased time of stick-slip oscillations while in the distributed-lumped model the vibration increases with increases the time interval of stick-slip motion.

7- The general trend of the angular velocities of rotary table $\left(\omega_{r t}\right)$ and drill bit $\left(\omega_{b}\right)$ in the distributed-lumped model is very similar to the actual measurement of the angular velocities in the actual system, as shown, in Figure 2 , when the length of the drill pipe $\left(l_{d p}\right)$ is equal to $2000 \mathrm{~m}$.

8- The fluctuating in the applied load of distributed-lumped and lumped model is similar in case one but with increased length of the drill pipe the difference between the two models increases. 
9- The shape of fluctuating in the applied load in lumped models is constant in all three cases while in the distributed-lumped model this fluctuates with the increase in the length of the drill pipe. This is similar to the behaviour of the torque in drilling due to the decreasing torsional stiffness of the drill pipe, with increasing length.

\section{References:}

1. Baker Houghes INTEQ. 1996. Oil field familiarization: Train Gudie. Baker Houghes INTEQ., Houston, Tx 7703, United States of America.

2. Navarro-Lopez EM, Suarez R. 2004. Practical approach to modelling and controlling stick-slip oscillations in oilwell drillstrings, abstr 2004 IEEE International Conference on Control Applications, September 2, 2004 - September 4, 2004, Taipei, Taiwan, Institute of Electrical and Electronics Engineers Inc.,

3. Schwarz RJ, Friedland B. 1965. Linear systems. McGraw-Hill, London; New York; etc.

4. Brett JF. 1992. The Genesis of Torsional Drillstring Vibrations. SPE Drilling Engineering 7:169-174.

5. Kriesels PC, Keultjes WJG, Dumont P, Huneidi I, Furat A, Owoeye OO, Hartmann RA. 1999. Cost Savings through an Integrated Approach to Drillstring Vibration Control, abstr in the SPE/IADC Middle East Drilling Technology Conference, Abu Dhabi., SPE/IADC 57555.,

6. Henneuse H. 1992. Surface detection of vibrations and drilling optimization: field experience, abstr Drilling Conference - Proceedings, February 18, 1992 - February 21, 1992, New Orleans, LA, USA, Publ by Soc of Petroleum Engineers of AIME,

7. Mensa-Wilmot G, Booth M, Mottram A. 2000. New PDC Bit Technology and Improved Operational Practices Saves 1M in CentralNorth Sea Drilling Program., abstr SPE/IADC Drilling Conference, New Orleans,

8. Placido JCR, Santos HMR, Galeano YD. 2002. Drillstring vibration and wellbore instability. Journal of Energy Resources Technology, Transactions of the ASME 124:217-222.

9. Macpherson JD, Jogi PN, Kingman JEE. 2001. Application and analysis of simultaneous near bit and surface dynamics measurements. SPE Drilling and Completion 16:230-238.

10. Warren TM, Oster JH. 1998. Torsional resonance of drill collars with PDC bits in hard rock, abstr Proceedings of the 1998 SPE Technical Conference and Exhibition Part Omega, September 27, 1998 - September 30, 1998, New Orleans, LA, USA, Soc Pet Eng (SPE), 
11. Patil PA, Teodoriu C. 2013. Model development of torsional drillstring and investigating parametrically the stick slips influencing factors. ASME J Energy Resour Technol 135:01310310131037.

12. Chen SL, Blackwood K, Lamine E. 2002. Field investigation of the effects of stick-slip, lateral, and whirl vibrations on roller-cone bit performance. SPE Drilling and Completion 17:15-20.

13. Halsey GW, Kyllingstad A, Kylling A. 1988. Torque feedback used to cure slip-stick motion, abstr Proceedings: 1988 SPE Annual Technical Conference and Exhibition, October 2, 1988 - October 5, 1988, Houston, TX, USA, Publ by Soc of Petroleum Engineers of AIME,

14. Lin Y-Q, Wang Y-H. 1991. Stick-slip vibration of drill strings. Journal of engineering for industry 113:38-43.

15. Jansen JD, van den Steen L. 1995. Active damping of self-excited torsional vibrations in oil well drillstrings. Journal of Sound and Vibration 179:647-668.

16. Pavković D, Deur J, Lisac A. 2011. A torque estimator-based control strategy for oil-well drill-string torsional vibrations active damping including an auto-tuning algorithm. Control Engineering Practice 19:836-850.

17. Tikhonov VS, Safronov AI. 2011. Analysis of postbuckling drillstring vibrations in rotary drilling of extended-reach wells. Journal of Energy Resources Technology, Transactions of the ASME 133: :0431021-0431028.

18. Armstrong-Helouvry B, Dupont P, Canudas De Wit C. 1994. Survey of models, analysis tools and compensation methods for the control of machines with friction. Automatica 30:1083-1138.

19. Leine RI. 2000. Bifurcations in discontinuous mechanical systems of filippov-type. Ph.D. Thesis. Technical University of Eindhoven, Netherlands.

20. Leine RI, Van Campen DH, De Kraker A, Van Den Steen L. 1998. Stick-slip vibrations induced by alternate friction models. Nonlinear Dynamics 16:41-54.

21. Karnopp D. 1985. COMPUTER SIMULATION OF STICK-SLIP FRICTION IN MECHANICAL DYNAMIC SYSTEMS. Journal of Dynamic Systems, Measurement and Control, Transactions of the ASME 107:100-103.

22. Whalley R. 1988. The response of distributed-lumped parameter system. Proceedings of the Institution of Mechanical Engineering, Part C: Journal of Mechanical Engineering Science 202:9.

23. Whalley R. 1990. Interconnected spatially distributed systems. Transactions of the Institute of Measurement and Control 12:262-270.

24. Rizvi SSI. 1998. Modelling and simulation of marine power transmissions systems: applying distributed-lumped (Hybrid) modelling techniques to marine power transmission system modelling and simulation for ship propulsion dynamics. Dissertation/Thesis. Bradford.

25. Whalley R, A-Ameer A. 2009. The computation of torsional, dynamic stresses. Proceedings of the Institution of Mechanical Engineers 223:1799-1814. 
26. Omojuwa E, Osisanya S, Ahmed R. 2012. Measuring and controlling torsional vibrations and stickslip in a viscous-damped drillstring model, abstr International Petroleum Technology Conference 2012, IPTC 2012, February 7, 2012 - February 9, 2012, Bangkok, Thailand, Univeristy of Zagreb,

27. Dufeyte M, Henneuse H. 1991. Detection and monitoring of the slip-stick motion: field experiments., abstr in Proceedings of the SPE/IADC Drilling Conference, Amsterdam, The Netherlands, March, 1991.

28. Jansen JD, van den Steen L, Zachariasen E. 1995. Active damping of torsional drillstring vibrations with a hydraulic top drive. SPE Drilling and Completion 10:250-254.

29. Christoforou AP, Yigit AS. 2003. Fully coupled vibrations of actively controlled drillstrings. Journal of Sound and Vibration 267:1029-1045.

30. Navarro-López EM, Licéaga-Castro E. 2009. Non-desired transitions and sliding-mode control of a multi-DOF mechanical system with stick-slip oscillations. Chaos, Solitons and Fractals 41:2035-2044.

\section{APPENDIX}

\section{A. Nomenclature}

$C_{m s}$

$C_{d p}$

$\mathrm{C}_{e b}$

$d_{i, d p}, d_{o, d p}$

G

$J_{m}, J_{r t}$

$J_{m s}, J_{d s}$

$J_{d p}, J_{h d p}, J_{d c}$

$\mathrm{J}_{l}$
Equivalent viscous damping of drive system $(\mathrm{Nms} / \mathrm{rad})$

Equivalent viscous damping coefficient along the drill pipe ( $\mathrm{Nms} / \mathrm{rad}$ )

Equivalent viscous damping of the bottom hole assembly ( $\mathrm{Nms} / \mathrm{rad}$ )

Inner and outer diameter of the drill pipe $(\mathrm{mm})$

Shear modulus of distributed shaft $\left(N / \mathrm{m}^{2}\right)$

Mass moment of inertia of motor and rotary table $\left(\mathrm{kgm}^{2}\right)$

Equivalent mass moment of inertia at motor side and drill string $\left(\mathrm{kgm}^{2}\right)$

Mass moment of inertia of the drill pipe, HWDP and drill collar $\left(\mathrm{kgm}^{2}\right)$

Mass moment of inertia of load $\left(\mathrm{kgm}^{2}\right)$

Shaft polar moment of inertia $\frac{\pi}{32} \mathrm{~d}^{4}\left(m^{4}\right)$ 
L

$l_{d p}, l_{d c}, l_{h d p}$

$K_{d p}$

$n$

$R_{b}$

$T_{m}, T_{r t}$

$T_{f b}$

$T_{a b}$

$T_{s b}, T_{c b}$

$W_{O b}$

$\delta \omega$

$\gamma$

$\gamma_{b}$

$\Gamma$

$\xi$

$\mu_{b}$

$\mu_{c b}$

$\mu_{s b}$

$\theta_{m}, \theta_{r t}, \theta_{b}$

$\theta$

$\rho$

$\omega_{r t}, \omega_{b}$
Shaft's inertia per unit length

Length of drill pipe, drill collar and $\operatorname{HWDP}(m)$

Equivalent torsional stiffness of the drill pipe $(\mathrm{Nm} / \mathrm{rad})$

A combined gear ratio of gearbox and bevel gear

Radius of the bit $(m)$

Torque of motor and rotary table $(\mathrm{Nm})$

Friction torque on the bit $(\mathrm{Nm})$

External torque applied by drill string on the bit $(\mathrm{Nm})$

Static and sliding friction torque on the bit $(\mathrm{Nm})$

Weight on bit (WOB) $(N)$

Limit velocity interval (rpm)

Shear strain

Positive constant defining the decaying velocity of $T_{\text {fob }}$

Propagation constant of the distributed shaft $(\mathrm{s} / \mathrm{m})$

Characteristic impedance of distributed shaft ( $\mathrm{Nms}$ )

Friction coefficient at the bit

Coulomb friction coefficient

Static friction coefficient

Angular displacement of motor, rotary table and bit ( $\mathrm{rad}$ )

Angle of twist (rad)

Density of steel $\left(\mathrm{kg} / \mathrm{m}^{3}\right)$

Angular velocities of rotary table and bit $(\mathrm{rev} / \mathrm{min})$ 


\section{B. List of Abbreviation}

\begin{tabular}{|l|l|}
\hline Abbreviation & Meaning \\
\hline D-L & Distributed-Lumped \\
\hline L & Lumped \\
\hline WOB & Weight-on-Bit \\
\hline BHA & Bottom Hole Assemble \\
\hline ROP & Rate of penetration \\
\hline HWDP & Heavy Weight Drillpipe \\
\hline TOB & Torque on Bit \\
\hline
\end{tabular}




\section{Model parameters}

The parameters used in this paper for simulation are corresponding to a real drill string design and similar to the parameter used by (28-30).

Table A-1 the parameters of simulation

\begin{tabular}{|l|c|c|c|}
\hline Name & Symbol & Value & Unit \\
\hline Shear modulus of steel & $G$ & $79.6 \times 10^{9}$ & $\mathrm{~N} / \mathrm{m}^{\wedge} 2$ \\
\hline Density of steel & $\rho$ & 7850 & $\mathrm{~kg} / \mathrm{m}^{\wedge} 3$ \\
\hline Radius of drill bit & $R_{b}$ & 0.155575 & $\mathrm{~m}$ \\
\hline Weight on drill bit & $W_{o b}$ & 80000 & $\mathrm{~N}$ \\
\hline Length of BHA and HWDP & $l_{d c}, l_{h w}$ & 150,110 & $\mathrm{~m}$ \\
\hline Outer and Inner diameters of drill pipe & $d_{o, d p}, d_{i, d r}$ & $127,108.6$ & $\mathrm{~mm}$ \\
\hline Outer and Inner diameters of HWDP & $d_{o, h w}, d_{i, h u}$ & $127,76.2$ & $\mathrm{~mm}$ \\
\hline Outer and Inner diameters of drill collar & $d_{o, d c}, d_{i, d c}$ & $228.6,76.2$ & $\mathrm{~mm}$ \\
\hline Gear ratio & $n$ & 7.2 & \\
\hline Inertia mass moment of motor and rotary table & $J_{m}, J_{r}$ & 23,930 & $\mathrm{kgm}$ \\
\hline Damping coefficient of the drive system & $C_{m s}$ & 425 & $\mathrm{Nms} / \mathrm{rad}$ \\
\hline Viscous damping along drill pipe(case 1,2 and 3) & $C_{d p}$ & $10,23,85$ & $\mathrm{Nms} / \mathrm{rad}$ \\
\hline Viscous damping along BHA (case 1,2 and 3) & $C_{e b}$ & $30,50,100$ & $\mathrm{Nms} / \mathrm{rad}$ \\
\hline Torsional stifness of drill pipe (case 1,2 and 3) & $K_{d p}$ & $1892,473,166$ & $\mathrm{Nm} / \mathrm{rad}$ \\
\hline Static friction coefficients & $\mu_{s b}$ & 0.8 & \\
\hline Coulomb friction coefficients & $\mu_{c b}$ & 0.5 & $\mathrm{rpm}$ \\
\hline The constant of decaying & $\gamma_{b}$ & 0.9 & $10-6$ \\
\hline A limit velocity interval & $\delta \omega$ & 10 & \\
\hline
\end{tabular}

